Wirtschaftswissenschaftliches Zentrum (WWZ) der Universität Basel

$\mathrm{WW} \mid \mathrm{Z}$

March 2014

\title{
A Theory of Trade Liberalization and Innovations with Heterogeneous Firms
}


Corresponding Author:

\section{Christian Rutzer, Assistant}

Abteilung Aussenwirtschaft und Europäische Integration

Wirtschaftswissenschaftliches Zentrum der

Universität Basel (WWZ)

Peter Merian-Weg 6

CH - 4002 Basel

+41(0)612673300

christian.rutzer@unibas.ch

A publication of the Center of Business and Economics (WWZ), University of Basel.

(C) WWZ 2013 and the authors. Reproduction for other purposes than the personal use needs the permission of the authors. 


\title{
A Theory of Trade Liberalization and Innovations with Heterogeneous Firms*
}

\author{
Christian Rutzer**
}

March 19, 2014

\begin{abstract}
This paper extends the firm heterogeneity model of Melitz (2003) by introducing a new concept of endogenous investments in process $R \& D$. The novelty is that if a firm invests more in $R \& D$ its expected innovation return hazard rate stochastically dominates the return of less $R \& D$ investments. Due to this property, entrants invest more in $R \& D$ in response to trade liberalization. As a result, the aggregate productivity is affected by a reallocation of resources to more productive firms and a simultaneous increase in firms' investments in innovations, which is consistent with empirical findings. At the same time the firms' increased $R \& D$ investments lead to a sector distribution with a higher right-tail compared to the distribution prior to trade liberalization. Hence, the model gives an explanation for the empirically found differences in the distribution tails among sectors with different trade openness levels. Another advantage of this paper's framework compared to other trade models with innovations is its foundation in and extension of Melitz (2003). It enables most of the heterogeneous firms trade models to be extended by endogenous firm-level $R \& D$ in an empirically relevant and analytically tractable way.
\end{abstract}

JEL-Classification: F12, F13, O31

Keywords: Aggregate Level, Firm Size Distribution, Heterogeneous Firms, $R \& D$ Investments, Trade Liberalization.

${ }^{*}$ I would like to thank Klara Buchner, Carsten Eckel, Tobias Erhardt, Benjamin Jung, Florian Kuhlmey, Maike Lengemann, Matthias Minke, Cyril Monnet, Horst Raff, Ulrich Schetter, Beat Spirig, Rolf Weder, Jens Wrona and the participants at the Gerzensee Alumni Conference and at the 16th Göttinger Workshop of International Economics for helpful comments and suggestions. In addition, I would like to thank Hermione Miller-Moser for editorial assistance.

${ }^{* *}$ Department of Economics, University of Basel, Switzerland. E-mail: christian.rutzer@unibas.ch. Any comments are greatly welcome. 


\section{Introduction}

A vast number of empirical evidence shows that trade liberalization increases the productivity of sectors substantially. In general, this aggregate productivity gains can be linked to a reallocation of resources towards more productive firms and productivity growth within firms (Lileeva, 2008; Fernandes, 2007; Bernard et al., 2006; Trefler, 2004; Pavcnik, 2002). One very important cause for the within firm productivity growth is an increase in investments in innovations (Bustos, 2011; Lileeva and Trefler, 2010). ${ }^{1}$ In addition, other studies find that trade liberalization leads to more dispersion of firms' productivity within a sector (Maggioni, 2013; Ito and Lechevalier, 2009; Syverson, 2004) and systematically affects the shape of a sector's firm productivity distribution (Okubo and Tomiura, 2013; Sun and Zhang, 2012; Di Giovanni et al., 2011).

From a theoretical point of view, the reallocation channel has been widely analyzed since the seminal heterogeneous firms trade framework by Melitz (2003). In these early heterogeneous firms trade models that allow an analysis of aggregate effects, firms can only respond to trade liberalization by adapting their entry, exit or export decision (Melitz and Ottaviano, 2008; Bernard et al., 2003; Melitz, 2003). ${ }^{2}$ As a result, the sector productivity changes solely due to a reallocation of resources from lowly productive exiting firms towards highly productive exporting firms. This selection leads to a higher average productivity of a sector, because the productivity distribution is now more truncated to the left. However, at odds with empirical results, the productivity dispersion within a sector decreases with trade openness. At the same time the shape of a sector's productivity distribution is unaffected. Hence, the consideration of both, within firm productivity change and firm selection seems to be crucial to match empirical facts on how trade liberalization affects aggregate productivity.

The aim of this paper is to provide a model consistent with above mentioned empirical facts. In doing so it complements existing heterogeneous firms and innovation models in two ways. From an economic perspective, trade liberalization leads to an increase in industry productivity due to a reallocation of resources to more productive firms and a simultaneous increase in firms' investments in innovations. To the best of the author's knowledge, the increase of aggregate industry productivity that is attributable to the combination of both, more innovation investments of firms and a selection effect, does not appear in any other theoretical model as yet. In addition, in accordance with empirical findings mentioned above, the increased $R \& D$ investments of firms lead to

\footnotetext{
${ }^{1}$ Additionally, trade liberalization can affect within firm productivity for example, by enabling a better access of firms to intermediate inputs (Amiti and Konings, 2007) or through a better reallocation of resources within firms for the purpose of product diversification (Bernard et al., 2011). An overview on what determines productivity in general is given in Syverson (2011). This survey also describes different channels on how trade liberalization influences productivity.

${ }^{2}$ For previous literature, see for example, Helpman (2006) and Greenaway and Kneller (2007) or more recent publications by Melitz and Redding (2012) and Melitz and Trefler (2012).
} 
more productivity dispersion and a higher right-tail of a sector's productivity distribution. Hence, the model delivers an explanation why trade liberalization can lead to an increase in the productivity dispersion and a more right-skewed distribution of firms. In a technical sense, it provides a simple and straight-forward extension of the wellestablished Melitz (2003) model. The paper adds a pre-stage to Melitz (2003) with Pareto-distributed firms in which a firm can decide on the size of process $R \& D$ investments. ${ }^{3}$ If a firm invests more in $R \& D$, it draws its productivity from a Pareto distribution that hazard rate stochastically dominates the Pareto distribution in case of less $R \& D$ investments, i.e. the distributions differ with respect to the shape parameter. This idea fits well with empirical evidence on innovation returns in a long run perspective (Leitner and Stehrer, 2011; Coad and Rao, 2008; Ebersberger et al., 2008; Scherer and Harhoff, 2000). They are highly uncertain and follow approximately a Pareto-distribution. In addition, innovation returns have a higher right-tail in sectors with high innovation activities like high-tech manufacturing or knowledge intensive services (Marsili, 2005; Marsili and Salter, 2005).

In the model, these exogenously given Pareto distributions can be seen as the general knowledge stock for the firms of an "adapting industry". The general knowledge is crucial because it determines the possibilities of subsequent applied $R \& D$ of such firms. These investments in turn determine their productivity (Cohen, 2010; Cohen and Levinthal, 1989). A more illustrative example on a practical level would be knowledge in electrical engineering, which is, in principle, available to all firms within an "adapting industry", for example the car-industry. The applied innovations of firms within the car-industry are limited beside other factors by the general knowledge in electrical engineering.

According to the model, the $R \& D$ investments of each individual firm depend on the aggregate level, which, in turn is influenced by all individual firm decisions taken together. This is similar to the industrial organization literature of free entry and $R \& D$ (Sutton, 1996; Dasgupta and Stiglitz, 1980). Trade liberalization raises in the model of this paper a firm's expected export profits while at the same time lowering its expected domestic profits due to more import penetration. In contrast to other heterogeneous firms trade models and endogenous innovation (Long et al., 2011; Atkeson and Burstein, 2010), the incentive of a single firm to invest more in $R \& D$ as trade costs fall is not offset by stronger competition. Hence, at some degree of trade openness, a firm prefers to invest a higher amount of sunk costs in order to draw from a more favorable Pareto distribution. Other firms will behave symmetrically because they share the same knowledge stock under the same conditions prior to their productivity draw.

\footnotetext{
${ }^{3}$ There are in general two types of profit seeking $R \& D$ investments possible (Syverson, 2011). On the on hand, investments in process $R \& D$ is conducted to make production of an output good more efficient. On the other hand, $R \& D$ investments in product innovations aim to invent a new product or to increase the product quality.
} 
At the new equilibrium, it is more profitable for each firm to invest more in $R \& D$. As a result, the aggregate level is now determined by a productivity distribution with a higher right-tail compared to the distribution prior to trade liberalization.

At any given level of trade openness, this model simply is a Melitz (2003) model, but with Pareto-distributed firms. The essential new feature here is, however, that the equilibrium distribution, which defines the sector productivity, is now endogenously determined by the $R \& D$ choice of firms. The choice, in turn, depends on the degree of trade openness. This important and novel result is attributable to innovation outcomes which differ according to the hazard rate stochastic dominance criterion. If $R \& D$ outcomes would only differ due to the first order stochastic dominance criterion, the optimal $R \& D$ investment level of a firm does not change with trade liberalization. An example is distinct Pareto distributions according to the minimum support. ${ }^{4}$

Much of the recent literature on heterogeneous firms is built around the Melitz (2003) conventions and assumes productivity draws that are Pareto distributed. For this reason, the $R \& D$ framework can be extended in various ways to gain new insights into the effects of trade liberalization at an industry level. ${ }^{5}$ Furthermore, the framework can be used in calibration exercises to consider endogenous changes in the shape of the firm distribution. This is important, because "international trade systematically changes the distribution of firm size, and inference that does not take that into account will likely lead to biased estimates" (Di Giovanni et al., 2011, p. 43).

This paper is part of the increasing literature on trade with heterogeneous firms and endogenous process $R \& D$ investments. In particular, it focuses on the impact of trade liberalization from a long term general equilibrium perspective. The model is therefore most closely associated with the work of Long et al. (2011). In their oligopoly model with linear demand, entrants can also choose how much to invest in process $R \& D$ before knowing their productivity. The benefit of modeling firm heterogeneity in an oligopolistic market structure rather than in a monopolistic competition market structure is that trade liberalization leads to empirical relevant mark-up adjustments (Bernard et al., 2012). However, in their model, the expected profits of process innovations after trade liberalization are exactly offset by stronger competition caused by firms entering the market. Hence, the innovation activity of a firm remains constant for any level of trade openness in case of free entry. It follows that the aggregate effects of trade liberalization are identical to usual heterogeneous firms models and are solely caused by the selection effect.

\footnotetext{
${ }^{4}$ Pflüger and Suedekum (2013) and Bohnstedt et al. (2012) show that governments will increase their $R \& D$ spending in response to trade liberalization in a model, in which increased $R \& D$ spending changes the technological potential summarized by the minimum support parameter of a Pareto distribution. However, they do not focus on $R \& D$ investments of firms.

${ }^{5}$ The list of heterogeneous firms trade models with Pareto distributed firms is huge. Prominent papers are, for example, Eaton et al. (2011); Baldwin and Nicoud (2008); Chaney (2008) and Helpman et al. (2004).
} 
Atkeson and Burstein (2010) study the impact of trade liberalization in a dynamic Melitz (2003) framework. In this model, firms can continuously decide on their $R \& D$ intensity. One key result is that, independent of the degree of trade openness, high productive export firms invest more in process $R \& D$ than low productive non-export firms. Yet, in the long run, incentives of firms to increase their productivity enhancing measures in response to trade liberalization are again offset by firm exit and entry. Hence, aggregate measures only change because of the selection effect. Moreover, they have to rely on numerical methods to derive most of the results, whilst the present model analyzes trade liberalization analytically. ${ }^{6}$ Vannoorenberghe (2009) suggests a further model in which firms can decide on how much to innovate after resolving uncertainty about productivity. In this extended Melitz (2003) model, trade liberalization may lead to an increase in $R \& D$ investments by firms even under consideration of general equilibrium effects. Yet, the framework separately analyzes the investment intensity at the firm level on the one hand and at the aggregate level on the other hand. Thus, it is hardly possible to assess the impacts of trade liberalization on sector productivity or welfare.

Other related papers, such as Unel (2013); Bustos (2011) and Navas-Ruiz and Davide (2007) study the impact of trade liberalization on technology adaption in Melitz (2003) style models. ${ }^{7}$ Their general result is that, in line with empirical evidence (Bustos, 2011; Lileeva and Trefler, 2010), more productive exporting firms adapt to better technology in response to trade liberalization, whereas less productive non-exporting firms do not. Again, the aggregate productivity is affected only by a selection effect because the shape of the underlying distribution does not change. Nevertheless, if the possibility of technology adaption is considered, it is stronger than in ordinary Melitz (2003) models.

There is one main difference between $R \& D$ as presented in the paper at hand and the technology adaption models named above. In the present model, an increase in $R \& D$ spending raises a firm's probability of realizing a higher productivity, but the exact level remains undefined. In the case of technology adaption models, however, a firm knows exactly by how much its productivity will increase. This difference can be interpreted as a long term perspective chosen in this paper compared to a short/medium term focus in technology adaption models. In the long run, firms may use entire new production processes, which to develop exhibit high uncertainty. Meanwhile, from a short/medium term perspective, firms may rather upgrade an already existing produc-

\footnotetext{
${ }^{6}$ Burstein and Melitz (2011) use a similar model to Atkeson and Burstein (2010) and study transition dynamics of trade liberalization. Another related paper is Costantini and Melitz (2007). They also study transition dynamics of trade liberalization in combination with the timing of the innovation decision.

${ }^{7}$ Ederington and McCalman (2008) or Yeaple (2005) also study how trade liberalization affects technology adaption. However, in their models, sector heterogeneity is a result of firms that adapt to different technologies and not the other way around.
} 
tion process.

Seen from a wider angle, the model relates also to the literature of endogenous growth and trade liberalization. All previously mentioned studies have in common that they focus on how trade liberalization affects firms' investments in innovations or adoption to an existing technology by taking the technology level or the general capability of firms to apply $R \& D$ as exogenously given. In contrast, endogenous growth models generally analyze, how trade liberalization affects the economy's wide technological progress. ${ }^{8}$ Recently, several studies (Unel, 2010; Gustafsson and Segerstrom, 2010; Baldwin and Nicoud, 2008) have embedded the heterogeneous firms trade model of Melitz (2003) into endogenous growth models à la Grossman and Helpman (1991) or Romer (1990). These models analyze how trade liberalization affects the knowledge accumulation in the presence of heterogeneous firms. In contrast to the model developed in this paper, the decisions of firms are equivalent to conventional heterogeneous firms models. In all of these models, a single firm takes the economy's wide knowledge as given and cannot conduct any productivity enhancing investments.

The remainder of the paper is structured as follows. Section two introduces the model by first describing the $R \& D$ choice of an entrant and subsequently determining the general equilibrium. Section three analyzes how trade liberalization changes the $R \& D$ choice and how this affects the aggregate level. Section four discusses some pros and cons of the proposed $R \& D$ concept and its embedding into the literature. Section five summarizes the main results.

\section{The model}

The main assumptions in our model are similar to those presented in the open economy section of Melitz (2003) in the case of two symmetric countries and no dynamics. ${ }^{9}$ But there are two significant differences. First, entrants draw their productivity from an explicit distribution, i.e. a Pareto distribution. This is, as mentioned in the introduction, standard in much of the literature on heterogeneous firms. Second, in contrast to other heterogeneous firms models, an entrant can choose to draw from two distinct Pareto distributions with respect to the parametric shape that these have. In the following, the word entrant will be used as the term for a firm before it has drawn its productivity. The word firm will be used as the term for a firm after it has drawn its productivity. The nominal wage rate serves as the numéraire and is set equal to one. Melitz (2003) assumes standard CES consumer preferences and derives domestic profits

\footnotetext{
${ }^{8} \mathrm{~A}$ review of the literature on trade and growth gives Segerstrom (2011).

${ }^{9}$ Melitz (2003) assumes an exogenous firm exit probability of $\delta$. This exit rate is not needed and will therefore be omitted from consideration.
} 
of a firm with productivity $z$ as

$$
\pi_{d}(z)=\frac{R}{\sigma}\left(P z \frac{\sigma-1}{\sigma}\right)^{\sigma-1}-f_{d}
$$

where $R$ denotes aggregate revenue, $P$ the aggregate price index, $\sigma$ the constant elasticity of substitution between two consumed varieties, and $f_{d}$ the fixed costs required to remain in the domestic market. Only firms with a high enough productivity draw to earn non-negative profits remain in the market. The productivity at which a firm has sufficient productivity to earn exactly zero profits in the domestic market is implicitly defined as $\pi_{d}\left(z_{D}\right)=0$. This threshold productivity value $z_{D}$ can be calculated by setting (1) equal to zero as

$$
z_{D}=\left(\frac{f_{d} \sigma}{R}\right)^{\frac{1}{\sigma-1}} \frac{\sigma}{(\sigma-1) P} .
$$

In addition, a firm that exports has to pay fixed costs $f_{x}$ and variable trade costs of Iceberg type $\tau \geq 1$ per unit shipped. The export profits of a firm with productivity $z$ can be written as

$$
\pi_{x}(z)=\frac{R}{\sigma}\left(P z \frac{\sigma-1}{\tau \sigma}\right)^{\sigma-1}-f_{x}
$$

The export market threshold productivity $z_{X}$ is equivalent to the domestic market threshold, defined as $\pi_{x}\left(z_{X}\right)=0$. Its value can be stated as a function of $z_{D}$ by using (2) and (3):

$$
z_{X}=\frac{z_{D}}{\phi}
$$

where some variables are merged to $\phi=\frac{1}{\tau}\left(\frac{f_{d}}{f_{x}}\right)^{\frac{1}{\sigma-1}}$, with $0 \leq \phi \leq\left(\frac{f_{d}}{f_{x}}\right)^{\frac{1}{\sigma-1}}$. This expression can be interpreted as a measure of trade openness, where autarky would be $\phi=0$ and free trade $\tau=1 \rightarrow \phi=\left(\frac{f_{d}}{f_{x}}\right)^{\frac{1}{\sigma-1}}$. As in the standard model of Melitz (2003), only the most productive firms export. The formal requirement for this is $z_{X}>z_{D}$. This is fulfilled as soon as $f_{x} \tau^{\sigma-1}>f_{d}$. In addition, because of additive fixed costs and market independent sunk $R \& D$ costs, all firms that export also sell in the domestic market.

An entrant can choose between two different $R \& D$ investments determining the distri- 
bution from which to draw its productivity. ${ }^{10}$ Its densities are

$$
f_{L}\left(z \mid z \geq z_{0}\right)=\theta_{L} \frac{z_{0}^{\theta_{L}}}{z^{\theta_{L}+1}} \quad \text { or } \quad f_{H}\left(z \mid z \geq z_{0}\right)=\theta_{H} \frac{z_{0}^{\theta_{H}}}{z^{\theta_{H}+1}}
$$

with $z_{0}$ as the minimum possible productivity draw. Both distributions differ with respect to the shape parameter $\theta$, where $\theta_{L}>\theta_{H}$. This leads to different right-tails as it can be seen from figure 1 . The distribution with the lower shape parameter value,

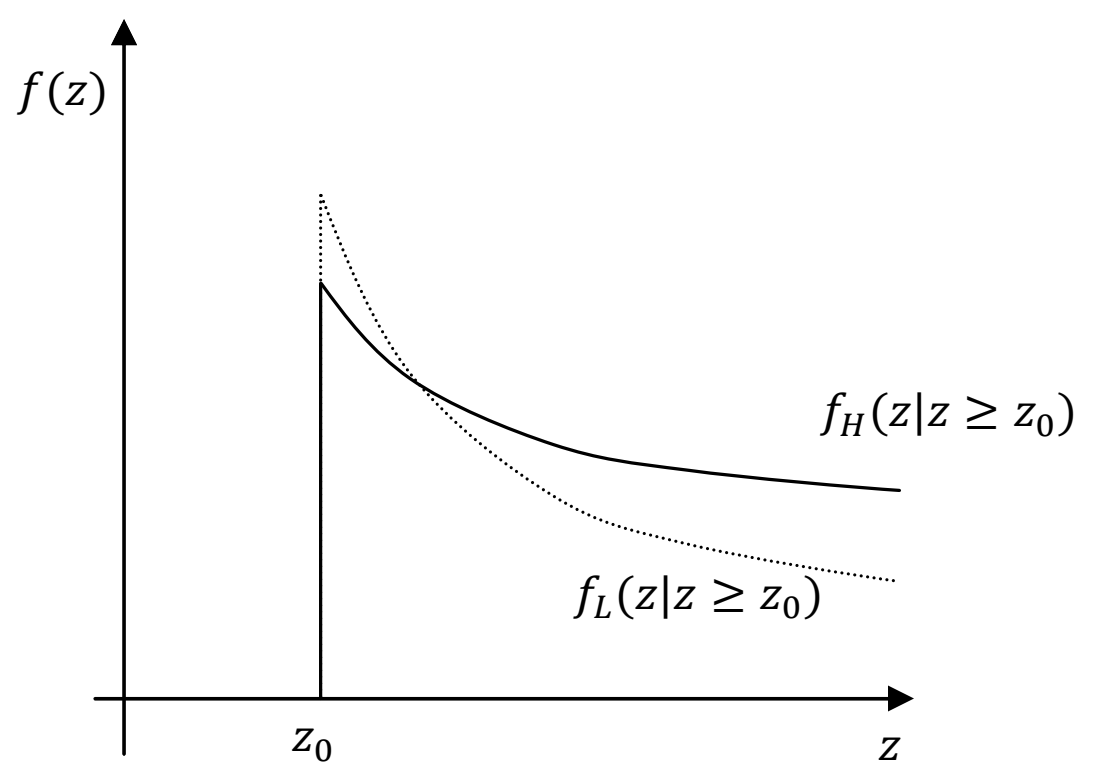

Figure 1: Distribution of Innovation Returns for a low level and a high level of $R \& D$ Investments.

$F_{H}(z)$, hazard rate stochastically dominates $(H R S D)$ the other distribution $F_{L}(z)$. If one distribution $H R S D$ another distribution, it means the probability to draw a productivity above any given cut-off level is higher for the dominant distribution than for the dominated distribution. In other words, survival is more likely if you draw from the better distribution according to the $H R S D$ criterion. Formally, a distribution function $F_{H}(z) H R S D$ a distribution function $F_{L}(z)$, if for any possible productivity draw $z$

$$
\frac{f_{H}(z)}{1-F_{H}(z)} \leq \frac{f_{L}(z)}{1-F_{L}(z)}
$$

is fulfilled. ${ }^{11}$ Instead of, a distribution first order stochastically dominates (FOSD) another distribution, if $F_{L}(z)>F_{H}(z)$ for all possible $z$ is fulfilled. Furthermore, $H R S D$ implies FOSD but not the other way around (for mathematical details see for example

\footnotetext{
${ }^{10}$ This is only for explanatory purposes. It is shown in the Appendix that the results do not change if there are a larger number of $R \& D$ choices available to an entrant. Thus, the function comes closer to a continuous optimization, which might be considered in future research.

${ }^{11}$ As later on discussed, the results of the model requires $H R S D$. In addition, the formal proof is derived in the Appendix
} 
Shaked and Shanthikumar (2007)).

Hence, for every possible productivity $z \geq z_{0}$, the probability to draw at least $z$ is higher under $f_{H}(z)$ than under $f_{L}(z)$. Furthermore, the dispersion of possible productivity draws is higher in the first case, because they are more scattered to the right. This implies that if an entrant is willing to invest more in $R \& D$, by paying a higher sunk investment cost $F_{H}>F_{L}$, it draws from the "better" distribution and gains a higher expected productivity draw. From now on I refer in the case that an entrant draws from the $\theta_{H}$-distribution to a high value of $R \& D$ and in the case that it draws from the $\theta_{L}$-distribution to a low value of $R \& D$.

Modeling $R \& D$ in such a way captures some essential characteristics highlighted in the literature. $R \& D$ has an uncertain outcome. But if more resources are spent to $R \& D$, it will likely lead to better results (Cohen, 2010). In addition, empirical evidence suggests that in a long term perspective returns to innovation investments are highly skewed and follow approximately a Pareto distribution (Leitner and Stehrer, 2011; Coad and Rao, 2008; Ebersberger et al., 2008; Scherer and Harhoff, 2000). Furthermore, a higher amount of $R \& D$ expenditures seem to increase the right-skewness of such returns (Marsili, 2005; Marsili and Salter, 2005).

A micro-founded explanation for these distributions can be delivered by using a dynamic model, in which $R \& D$ investments influence the change of a firm's performance over time. The derivatives are available upon request for the particular case if each firm's productivity changes continuously according to a Brownian Motion. A firm's long term performance is in this case Pareto distributed. ${ }^{12}$ Furthermore, the shape parameter of the Pareto distribution depends on the expected growth rate of the Brownian motion. A higher expected growth rate leads to a Pareto distribution with a lower shape parameter. If now the expected growth rate depends on the size of $R \& D$ investments, such an $R \& D$ choice would lead in the long run to the same result as in this paper. However, modeling $R \& D$ in such a way is more complex. That is why this framework focuses on entrants drawing their productivity directly from exogenously given distributions.

An entrant seeks to maximize its expected firm value with respect to the $R \& D$ choice:

$$
V\left(z_{D}, \phi\right)=\max _{i}\left\{V_{i}\left(z_{D}, \phi\right)\right\}
$$

where the superscript $i \in\{L, H\}$ indicates the choice. The decision depends on the general equilibrium value $z_{D}$, which is exogenous from a firm's perspective, and on the degree of trade openness $\phi$. This max-argument function will from now on be called the $R \& D$ choice function. The expected firm value prior to the draw is in both

\footnotetext{
${ }^{12}$ Impullitti et al. (2013) consider dynamic productivity changes according to a Brownian motion in a Melitz (2003) framework. However, in their model firms cannot influence the drift of the Brownian motion.
} 
cases equivalent to expected profits from domestic and export sales minus the sunk investment costs: $V_{i}\left(z_{D}\right)=\pi_{i}\left(z_{D}, \phi\right)-F_{i}$, with $i=L, H$.

If an entrant finds it optimal to invest in the $\theta_{i}-R \& D$, it will enter into the domestic market if it has drawn a productivity larger than $z_{D}$. The probability is $P\left(z>z_{D}\right)=$ $\left(\frac{z_{0}}{z_{D}}\right)^{\theta_{i}}$. Hence, an entrant's output-weighted expected domestic market productivity is

$$
\tilde{z}_{i}=\left(\int_{z_{D}}^{\infty} z^{\sigma-1} \frac{\theta_{i} z_{D}^{\theta_{L}}}{z^{\theta_{i}+1}} d z\right)^{1 /(\sigma-1)} \rightarrow B_{i}^{\frac{1}{\sigma-1}} z_{D}
$$

with $B_{i}=\frac{\theta_{i}}{\theta_{i}-\sigma+1}>1 .{ }^{13}$ Furthermore, a firm with a productivity draw larger than $z_{X}$ will also export its product. The probability for this is $P\left(z>z_{X}\right)=\left(\frac{z_{0}}{z_{X}}\right)^{\theta_{L}}$. The output-weighted expected export market productivity is

$$
\tilde{z}_{X i}=\left(\int_{z_{X}}^{\infty} z^{\sigma-1} \frac{\theta_{i} z_{X}^{\theta_{i}}}{z^{\theta_{i}+1}} d z\right)^{1 /(\sigma-1)} \rightarrow B_{i}^{\frac{1}{\sigma-1}} z_{X}
$$

Using the domestic market cut-off (2) in the expected domestic market profits equation ((1) together with (8)), as well as the export market cut-off (4) in the expected exportmarket profits equation $((3)$ together with (9)) and then multiplying both with the corresponding probability of a successful entry, total expected profits of an entrant can be written as

$$
\pi_{i}\left(z_{D}, \phi\right)=\left(B_{i}-1\right)\left(f_{d}+f_{x} \phi^{\theta_{i}}\right)\left(\frac{z_{0}}{z_{D}}\right)^{\theta_{i}} .
$$

\subsection{Determination of the general equilibrium value}

An entrant decides to enter into the market as long as its expected value is larger or equal to zero. Furthermore, it chooses the value maximizing level of $R \& D$. Hence, the free entry condition can be written by using (7) and (10) as

$$
\left(B_{i}-1\right)\left(f_{d}+f_{x} \phi^{\theta_{i}}\right) z_{D}^{-\theta_{i}}-F_{i} \leq 0 .
$$

It determines endogenously the general equilibrium value $z_{D}$. Without loss of generality, the lowest possible productivity $z_{0}$ is set to $z_{0}=1$. In this case the value of $z_{D}$ has to be at least one. This bounds the parameter values to $\left(B_{i}-1\right)\left(f_{d}+f_{x} \phi^{\theta_{i}}\right) \geq F_{i}$. Otherwise no entry would take place at all. As long as the expected value for a $R \& D$ investment possibility is larger than zero, more entry takes place. This lowers expected

\footnotetext{
${ }^{13}$ The appropriate density function of all firms that remain in the market equals the density of all possible draws conditioned on successful draws: $f\left(z \mid z \geq z_{D}\right)=\frac{f(z)}{P\left(z \geq z_{D}\right)}=\frac{\theta_{i} z_{0}^{\theta_{i}}}{z^{\theta_{i}+1}}\left(\frac{z_{D}}{z_{0}}\right)^{\theta_{i}}$.
} 
profits for each $R \& D$ choice due to an increase in the competition intensity summarized by $z_{D}::^{14}$

$$
\frac{\partial V_{i}\left(z_{D}, \phi\right)}{\partial z_{D}}=-\theta_{i}\left(B_{i}-1\right)\left(f_{d}+f_{x} \phi^{\theta_{i}}\right) z_{D}^{-\theta_{i}-1}<0
$$

until the maximal expected value out of the two $R \& D$ choices is zero. The expected value of an entrant cannot be larger than zero in equilibrium. Figure 2 exemplify the expected home firm value for each $R \& D$ investment in dependency of the home market competition intensity $z_{D}$. If the competition intensity would be $z_{D}^{S}$, the expected profits of both kinds of $R \& D$ are larger than zero. This cannot be an equilibrium. More entry takes place. This let the competition intensity increase and the expected profits decline until the point $z_{D}^{H}$ is reached. The expected profits of a high level of $R \& D$ investment is zero at this level of competition. But investments in a low level of $R \& D$ still lead to a positive expected profit. Hence, further entry of firms that have invested in a low level of $R \& D$ takes place until the competition intensity is at $z_{D}^{L}$. At this competition intensity no further entry takes place, because investments in a low level of $R \& D$ leads to zero expected profits and investments in a high level of $R \& D$ to negative expected profits.

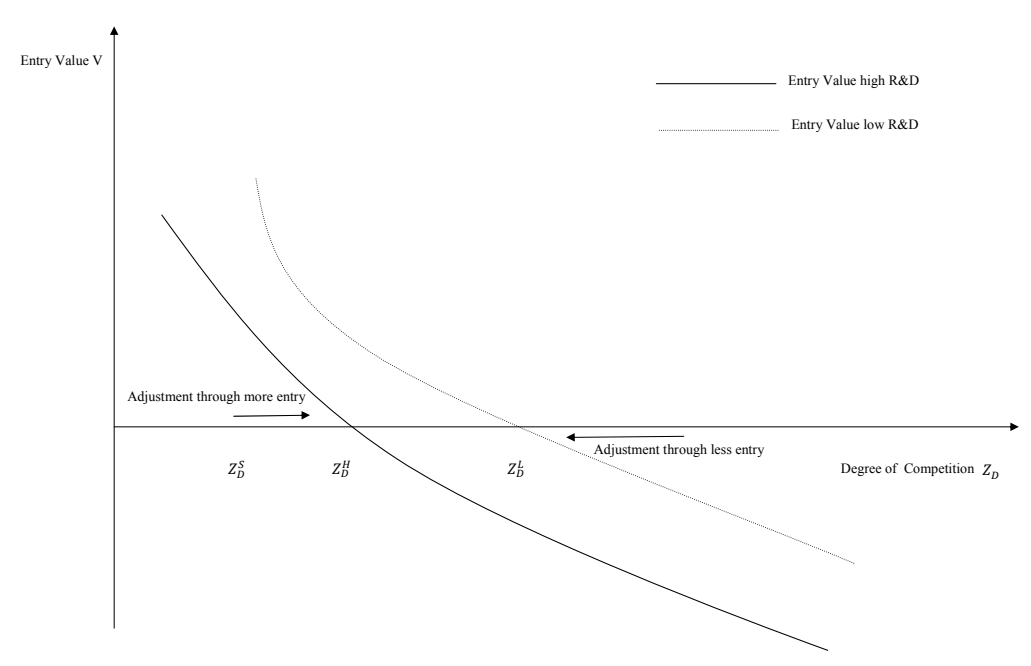

Figure 2: Determination of the equilibrium.

Hence, in contrast to heterogeneous firms models without endogenous firm level $R \& D$,

\footnotetext{
${ }^{14}$ There is some debate whether the general equilibrium effect works through the labor market competition or through the product market competition. Potin (2009) shows that the selection effect $z_{D}$ is influenced by both channels. However, all channels are summarized by $z_{D}$. Hence, only this value is crucial when analyzing how a change in the general equilibrium affects the expected profits of an entrant.
} 
the functional form of the free entry condition depends now on the size of $R \& D$ investments. The question is how to determine $z_{D}$ analytically. A single entrant is atomistically small and takes the aggregate level summarized by $z_{D}$ as given. The $R \& D$ choice of all firms together influence the aggregate level and the $R \& D$ choice of each individual entrant depends on the aggregate level. A two-way dependency of this kind is well known in the industrial organization literature of free entry and $R \& D$, as used, for example, in prominent works by Sutton (1996) or Dasgupta and Stiglitz (1980).

In this model the general equilibrium value $z_{D}$ is determined in two steps. In the first step, $z_{D}$ is calculated for all possible $R \& D$ choices: one where all entrants draw from $\theta_{L}$; another one where all entrants draw from $\theta_{H}$; and a third one, where a fraction of entrants draw from $\theta_{H}$ and the rest from $\theta_{L}$. In the next step, the $R \& D$ choice of a single entrant is analyzed for each possible general equilibrium value and in dependency of trade openness. Since all entrants are similar prior to the productivity draw, an equilibrium comes about if an entrant does not find it optimal to deviate from its $R \& D$ choice in the case where the general equilibrium value is determined by the same $R \& D$ choice.

If all firms were to draw from the $\theta_{L}$-distribution, the corresponding cut-off value would be $z_{D}=z_{D}^{L}$. If, instead, all firms were to draw from the $\theta_{H^{-}}$distribution, its value would be $z_{D}=z_{D}^{H}$. In both pure cases, the cut-off value is determined by the free-entry condition (11), given as

$$
z_{D}^{i}=\left(\frac{\left(B_{i}-1\right)\left(f_{d}+f_{x} \phi^{\theta_{i}}\right)}{F_{i}}\right)^{\frac{1}{\theta_{i}}} .
$$

If, instead, a fraction of $0<\lambda<1$ of firms have drawn their productivity from the $\theta_{L}$-distribution and $(1-\lambda)$ of firms from the $\theta_{H^{-}}$distribution, the cut-off value would be $z_{D}=z_{D}^{m i x}$. In this case, the cut-off value is defined implicitly by a linear combination of each argument of (11) as

$$
(1-\lambda)\left(B_{L}\left(f_{d}+f_{x} \phi^{\theta_{L}}\right)\left(z_{D}^{m i x}\right)^{-\theta_{L}}-F_{L}\right)+\lambda\left(B_{H}\left(f_{d}+f_{x} \phi^{\theta_{H}}\right)\left(z_{D}^{m i x}\right)^{-\theta_{H}}-F_{H}\right)=0 .
$$

Since $z_{D}^{m i x}$ is a weighted sum of $z_{D}^{L}$ and $z_{D}^{H}$, its value is, respectively lower (higher) than the highest (lowest) possible cut-off value, which results if all firms would have drawn from the same distribution, either from $\theta_{L}$ or $\theta_{H}$ :

$$
\min \left\{z_{D}^{i} ; z_{D}^{j}\right\}<z_{D}^{\operatorname{mix}}<\max \left\{z_{D}^{i} ; z_{D}^{j}\right\}
$$


as long as $z_{D}^{i} \neq z_{D}^{j}$ with $i, j \in\{L, H\}$ and $i \neq j$. Such a mixed equilibrium exists only, if a single entrant finds it optimal to make a mixed choice:

$$
(1-\lambda) V_{L}\left(z_{D}^{\operatorname{mix}}, \phi\right)+\lambda V_{H}\left(z_{D}^{\operatorname{mix}}\right) \geq \max \left\{V_{L}\left(z_{D}^{\operatorname{mix}}, \phi\right), V_{H}\left(z_{D}^{\operatorname{mix}}, \phi\right)\right\}
$$

But the left-hand side can never be larger than the right-hand side, because it is a linear combination of both possible values of the right-hand side max-argument function. It can only be that the left-hand side is equal to the right-hand side. This is the case, if $V_{L}\left(z_{D}^{m i x}, \phi\right)=V_{H}\left(z_{D}^{m i x}, \phi\right)$. However, in this case no equilibrium exists, because an entrant is indifferent between every possible mixed choice. It follows that no mixed equilibrium exists, because one of the two pure $R \& D$ choices, either $\theta_{L}$ with $\lambda=0$ or $\theta_{H}$ with $\lambda=1$, dominates the mixed choice. Which pure choice dominates and determines the equilibrium will depend on the degree of trade openness and will be analyzed next.

\subsection{Trade liberalization and $R \& D$ choice of entrants}

As in Melitz (2003) and other models with no dynamic adjustments, the following results are seen as a steady state comparison of different trade openness levels. Figure 3 displays the results that will be derived in this section analytically. It shows each $R \& D$ choice (7) as a function of trade openness $\phi$. Trade liberalization is interpreted as a reduction in variable trade $\operatorname{costs} \tau$, which is equivalent to a larger $\phi$ (see (4)). The figure shows that entrants prefer low $R \& D$ investments at low levels of trade openness. But as soon as trade becomes liberalized beyond $\phi^{*}$, entrants find it optimal to make a high level of $R \& D$ investment. The formal analysis follows now. First, we assume that all other entrants draw from the $\theta_{L}$-distribution and hence the general equilibrium

value is $z_{D}^{L}$ (see equation (13)). The $R \& D$ choice function of an entrant (7) is in this case as follows:

$$
V\left(z_{D}^{L}, \phi\right)=\max \left\{0 ;\left(B_{H}-1\right)\left(f_{d}+f_{x} \phi^{\theta_{H}}\right)\left(\frac{F_{L}}{\left(B_{L}-1\right)\left(f_{d}+f_{x} \phi^{\theta_{L}}\right)}\right)^{\frac{\theta_{H}}{\theta_{L}}}-F_{H}\right\} .
$$

The corresponding $z_{D}$ cut-off value (13), with $i=L$, was used in the entrant's profit function (10) to derive this expression. The first argument represents the expected firm value in the case that an entrant decides to draw from the $\theta_{L}$-distribution. Its value is zero due to free entry for any level of trade openness as long as all other entrants draw also from the $\theta_{L}$-distribution. However, if an entrant deviates and invest more in $R \& D$ and draws its productivity out of the $\theta_{H^{-}}$distribution, its expected value will be the second argument of equation (17), $V_{H}\left(z_{D}^{L}, \phi\right)$. The second argument of the $R \& D$ 


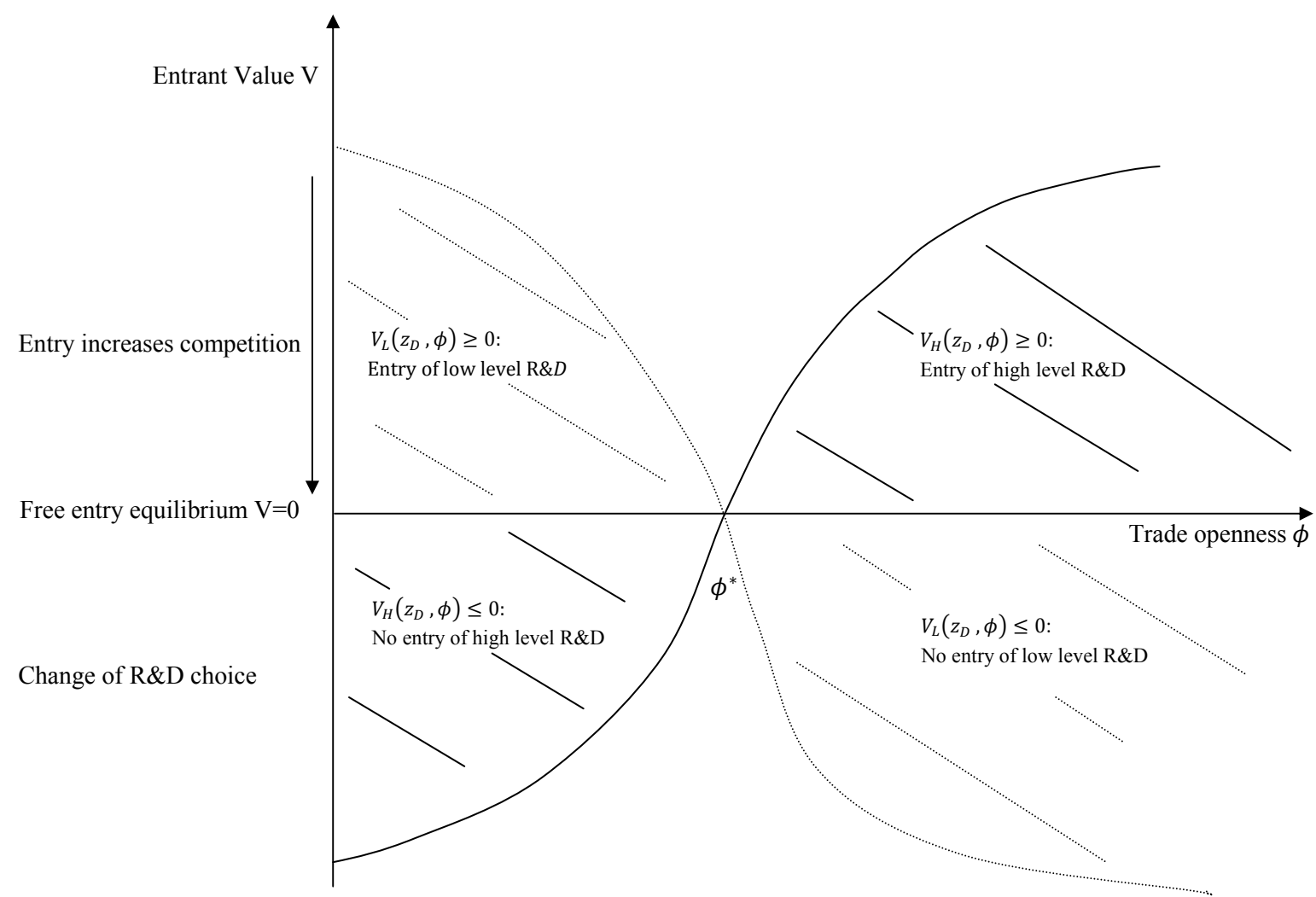

Figure 3: R\&D choice in dependency of trade openness $\phi$.

choice function increases as trade is liberalized:

$$
\frac{\partial V_{H}\left(z_{D}^{L}, \phi\right)}{\partial \phi}=\frac{\theta_{H}\left(\frac{F_{L}}{\left(B_{L}-1\right)}\right)^{\frac{\theta_{H}}{\theta_{L}}}\left(B_{H} f_{d} f_{x}-f_{d} f_{x}\right)\left(\phi^{\theta_{H}-1}-\phi^{\theta_{L}-1}\right)}{\left(f_{d}+f_{x} \phi^{\theta_{L}}\right)^{\frac{\theta_{H}+\theta_{L}}{\theta_{H}}}}>0 .
$$

The derivative is positive, because $B_{H}>1, \theta_{H}<\theta_{L}$ as well as $0<\phi<1$ and thus $\phi^{\theta_{H}}>\phi^{\theta_{L}}$. The incentive to invest in a high level of $R \& D$ and draw from the $\theta_{H^{-}}$ distribution increases. If an economy becomes more open, competition will rise in both markets and lead to lower expected profits (12); however, at the same time, expected export profits will increase. ${ }^{15}$ If entrants were to have no $R \& D$ choice, there would be an adjustment of the mass of entrants until both effects would cancel each other out. This is the case in conventional heterogeneous firms models as presented, for example, in Melitz (2003) and Melitz and Ottaviano (2008). The entrant value (11) would remain zero owing to free entry at any level of trade openness. This can be seen from (18) by setting $\theta_{L}=\theta_{H}: \frac{\partial V_{H}\left(z_{D}^{L}, \phi\right)}{\partial \phi}=0$.

In the present model, however, the relative profitability of high to low levels of $R \& D$ investment increases with a decline in trade costs. Due to (18), there exists a particular level of trade openness at which $V_{H}\left(z_{D}^{L}, \phi\right)=0$ if the sunk investment cost $F_{H}$ is not too

\footnotetext{
${ }^{15}$ The derivation of (10) with respect to trade openness is $\frac{\partial V_{i}\left(z_{D}, \phi\right)}{\partial \phi}=\theta_{i}\left(B_{i}-1\right) f_{x} \phi^{\theta_{i}-1} z_{D}^{-\theta_{i}}>0$ when the change in the competition intensity is not taken into account.
} 
high. Hence, an entrant can raise its expected overall profits above zero by investing in a high level of $R \& D$, even if the general equilibrium effects have been worked out, once trade has been liberalized beyond a particular level of trade openness. Spoken differently, the free entry condition is no longer fulfilled for investments in a high level of $R \& D$. Hence, the intensity of the competition is too weak in order to deter potential entrants from investing in a high level of $R \& D$ and try to get into the market. Other entrants will also take advantage of this possibility. As a result the competition intensity will increase (equation (12)). This leads to a decrease of the expected profits for both kinds of $R \& D$ investments, until drawing from the $\theta_{H}$-distribution will lead to zero expected profits, $V_{H}\left(z_{D}, \phi\right)-F_{H}=0$. However, the competition intensity is now too strong to have zero expected profits by investing in a low level of $R \& D, z_{D}>z_{D}^{L}$ $\rightarrow V_{L}\left(z_{D}, \phi\right)-F_{L}<0$.

Second, we assume now that all other entrants draw from the $\theta_{H^{-}}$distribution and hence the general equilibrium value is $z_{D}^{H}$ (see (13)). The $R \& D$ choice function of an entrant (7) is in this case

$$
V\left(z_{D}^{H}, \phi\right)=\max \left\{0 ;\left(B_{L}-1\right)\left(f_{d}+f_{x} \phi^{\theta_{L}}\right)\left(\frac{F_{H}}{\left(B_{H}-1\right)\left(f_{d}+f_{x} \phi^{\theta_{H}}\right)}\right)^{\frac{\theta_{L}}{\theta_{H}}}-F_{L}\right\}
$$

Here, once again, the firm profit function (10) as well as the corresponding cut-off value (13) with $i=H$ has been inserted in (7). The first argument is zero due to free entry as long as all other entrants draw also from the $\theta_{H^{-}}$distribution. Thus, an entrant will deviate and draw from the $\theta_{L}$-distribution instead of the $\theta_{H}$-distribution, only if the second argument is larger than zero. The deviation value depends negatively on the degree of trade openness:

$$
\frac{\partial V_{L}\left(z_{D}^{H}, \phi\right)}{\partial \phi}=-\frac{\theta_{L}\left(\frac{F_{H}}{\left(B_{H}-1\right)}\right)^{\frac{\theta_{L}}{\theta_{H}}}\left(B_{L} f_{d} f_{x}-f_{d} f_{x}\right)\left(\phi^{\theta_{H}-1}-\phi^{\theta_{L}-1}\right)}{\left(f_{d}+f_{x} \phi^{\theta_{H}}\right)^{\frac{\theta_{L}+\theta_{H}}{\theta_{L}}}}<0 .
$$

The inequality follows immediately from the minus. The relative profitability of high to low levels of $R \& D$ investment increases as trade becomes liberalized. This attracts more entrants as it would be the case if entrants invest in a low level of $R \& D$. Hence, the competition intensity increases more if the free entry equilibrium is determined by entrants investing in a high level of $R \& D$ than by entrants investing in a low level of $R \& D$. As a result, the positive direct effect of lower trade costs on the expected value of an entrant that decides to invest a low level of $R \& D$ is more than offset by the increased competition.

Now, it is possible to determine the optimal $R \& D$ choice of entrants. Since the incentive to invest in a high level of $R \& D$ increases monotonically (18) and, the incentive to invest in a low level of $R \& D$ declines monotonically (20) as trade becomes 
more liberalized, maximal one intersection point between $\phi=0$ and $\phi=1$ exists at which $V_{L}\left(z_{D}^{H}, \phi\right)$ and $V_{H}\left(z_{D}^{L}, \phi\right)$ are equal. An intersection point exists, if the condition $\left(f_{d}+f_{x} \phi^{\theta_{L}}\right)\left(\frac{F_{H}}{\left(B_{H}-1\right)\left(f_{d}+f_{x} \phi^{\theta} H\right)}\right)^{\frac{\theta_{L}}{\theta_{H}}}<\frac{F_{L}}{B_{L}-1}<f_{d}\left(\frac{F_{H}}{\left(B_{H}-1\right) f_{d}}\right)^{\frac{\theta_{L}}{\theta_{H}}}$ on the parameter values is fulfilled. The derivation of it can be found in the Appendix. It states that entrants find it optimal under autarky to invest in a low level of $R \& D$. In addition, from a certain degree of trade openness on they find it optimal to invest in a high level of $R \& D$. In the following, it is assumed that this intersection point defined as $\phi^{*}$ exists. It is shown in the Appendix that at this level of trade openness the general equilibrium value $z_{D}$ has the same value irrespective of whether all firms would draw from the $\theta_{H}$-distribution or the $\theta_{L^{-}}$distribution. Thus, $z_{D}^{H}=z_{D}^{L}=z_{D}^{m i x}$ at $\phi^{*}$ follows immediately, because $z_{D}^{m i x}$ is a combination of both pure general equilibrium values (see (14)). Hence, at $\phi^{*}$ an entrant is indifferent between drawing from one or the other distribution, because

$$
V_{H}\left(z_{D}^{i}, \phi=\phi^{*}\right)=V_{L}\left(z_{D}^{i}, \phi=\phi^{*}\right)
$$

As a result, at $\phi^{*}$ no equilibrium exists. ${ }^{16}$

For lower levels of trade liberalization, $\phi<\phi^{*}$, the unique stable choice is a low level of $R \& D$ investment. Owing to the previously derived result that an entrant makes no mixed choice as long as $\phi \neq \phi^{*}$, it is enough to analyze the behavior of an entrant at each pure general equilibrium value. By using the derivatives (18) and (20), it follows from $(21)$ that $V_{L}\left(z_{D}^{H}, \phi<\phi^{*}\right)>V_{H}\left(z_{D}^{H}, \phi<\phi^{*}\right)=0$ and $V_{L}\left(z_{D}^{L}, \phi<\phi^{*}\right)=0>V_{H}\left(z_{D}^{L}, \phi<\phi^{*}\right)$. A rational entrant will therefore never invest in a high level of $R \& D$ and draw from the $\theta_{H}$-distribution, because this choice is strictly dominated by an investment in a low level of $R \& D$. Since all entrants are similar prior to the productivity draw, they will all behave the same way and choose $\theta_{L}$. This in turn determines the general equilibrium value as $z_{D}^{L}$.

If, instead, trade is liberalized beyond $\phi^{*}$, it follows from (18), (20) and (21) that $V_{L}\left(z_{D}^{H}, \phi>\phi^{*}\right)<V_{H}\left(z_{D}^{H}, \phi>\phi^{*}\right)=0$ and $V_{L}\left(z_{D}^{L}, \phi>\phi^{*}\right)=0<V_{H}\left(z_{D}^{L}, \phi>\phi^{*}\right)$. Hence, for all openness levels larger than $\phi^{*}$ an entrant finds it optimal to invest in a high level of $R \& D$ and draw from the $\theta_{H^{-}}$distribution, because this choice strictly dominates an investment in a low level of $R \& D .{ }^{17}$ Hence, the unique stable equilibrium will be a high level of $R \& D$ investment with $z_{D}^{H}$ as the general equilibrium value.

\footnotetext{
${ }^{16}$ No pure equilibrium and no mixed equilibrium, where the entrants' choices are split between $\theta_{L}$ and $\theta_{H}$, exist.

${ }^{17}$ This argument still holds if trade becomes liberalized and incumbent firms are exposed to an exogenous exit rate $\delta$ as in Melitz (2003). As soon as trade is liberalized beyond $\phi^{*}$, an entrant finds it optimal to invest in a high level of $R \& D$ for all possible competition intensities $z_{D}$. In the beginning, all incumbent firms would have invested in a low level of $R \& D$. However, these firms are hit by the shock $\delta$. The new entrants will all invest in a high level of $R \& D$. The competition intensity increases step by step from $z_{D}^{L}$ to $z_{D}^{H}$ (see (15)) until all incumbent firms that have invested in a low level of $R \& D$ have exited the market.
} 
To gain intuition for these results consider investors that finance entrants. Each investor is equipped with sufficient funds to finance a large number of entrants. Furthermore, each entrant can choose from an unbounded pool of uncorrelated projects of the two types described previously. In the absence of asymmetric information and full enforceability of contracts, a profit maximizing investor will finance only projects with the highest expected return: $\max \left\{\frac{V_{i}\left(z_{D}, \phi\right)-F_{i}}{F_{i}}\right\}$ (or equivalent $\max \left\{\frac{\pi_{i}\left(z_{D}, \phi\right)}{F_{i}}\right\}$ ). This expression is equivalent to Tobin's famous $q$, the ratio of expected market value to replacement cost (Tobin, 1969). Consistent with the literature, it tend in the model to unity by free entry (see (11)). ${ }^{18}$ Investments in a high level of $R \& D$ leads for any level of trade openness to a higher expected productivity draw and a higher expected market value compared to low $R \& D$ investments. Hence, if an entrant has to decide once between both investments without taking the investment costs into account, she would always invest in a high level of $R \& D$. But as long as access to the foreign market is highly limited, an investment in a high level of $R \& D$ is not profitable, because the investment costs are too high relative to the expected sales opportunities. As a result, an investor will for low levels of trade liberalization only finance entrants that decide to carry out $\theta_{L}$-projects and for high levels of trade liberalization only finance entrants that innovate more and carry out $\theta_{H}$-projects. Eventually, trade liberalization changes the market structure fundamentally, which increases the pressure on each entrant to conduct more innovations to be funded by investors.

\subsection{Trade liberalization and sector productivity}

In the next step it will be analyzed what impacts the previously derived changes in $R \& D$ investments on firm level has on the sector productivity. The sector productivity is at a particular level of trade openness similar to Melitz (2003) for Pareto-distributed firms:

$$
\tilde{z}_{i}=\left(\frac{1}{1+p_{X}^{i}}\left(\tilde{z}_{D}^{i}{ }^{\sigma-1}+p_{X}^{i}\left(\tau^{-1} \tilde{z}_{X}^{i}\right)^{\sigma-1}\right)\right)^{\frac{1}{\sigma-1}}
$$

with $p_{X}^{i}$ as the share of export firms to all firms. The sector productivity is a weighted average between the productivity used to produce domestic sales, $\tilde{z}_{D}^{i}$, and the productivity used to produce exports, $\tilde{z}_{X}^{i}$, under consideration of the output shrinkage $\tau$ that reflects trade costs. In the case of Pareto distributed productivities, the sector productivity can be written by using (4), (8) and (9) as

$$
\tilde{z}_{i}=\left(\frac{1}{1+\phi^{\theta_{i}}}\left(B_{i} z_{D}^{i \sigma-1}+\tau^{1-\sigma} \phi^{\theta_{i}-\sigma+1} B_{i} z_{D}^{i \sigma-1}\right)\right)^{\frac{1}{\sigma-1}}
$$

\footnotetext{
${ }^{18}$ If Tobin's $q$ would be larger than one, more firms would enter. This increases the competition intensity summarized by $z_{D}$ until $q=1$.
} 
with $z_{D}^{i}=\left(\frac{\left(B_{i}-1\right)\left(f_{d}+f_{x} \phi^{\theta_{i}}\right)}{F_{i}}\right)^{\frac{1}{\theta_{i}}}$ as the equilibrium competition intensity. It depends now on the size of the $R \& D$ investments of entrants indicated by $i$, which depends on the degree of trade openness. The model would reduce to Melitz (2003) with Pareto distributed firms, if each entrant draws from the same distribution for any level of trade openness. As previously derived, for low levels of trade openness, $\phi<\phi^{*}$, all entrants invest in a low level of $R \& D$ and the equilibrium sector productivity is $\tilde{z}_{L}$. Furthermore, all entrants find it optimal after trade liberalization to invest in a high level of $R \& D$ and draw from a distribution that $H R S D$ the pre-trade liberalization preferred distribution. Figure 4 illustrates the difference between a model with and with no endogenous $R \& D$ investments. In the case of endogenous innovations, trade liberalization leads to a larger number of productive firms compared to a model without endogenous $R \& D$ investments. The impact on sector productivity differs according to two effects. First, the existents of more productive firms leads to a tougher competition. The tougher competition requires a higher productivity to survive. As a result the selection is stronger, which leads to a higher sector productivity: $z_{D}^{H}>z_{D}^{\prime}$ (effect $(1 a)$ vs. (1b) in Figure 4). This inequality follows immediately from the free entry adjustment, (11) and (12), and the level of competition at $\phi^{*},(21)$.
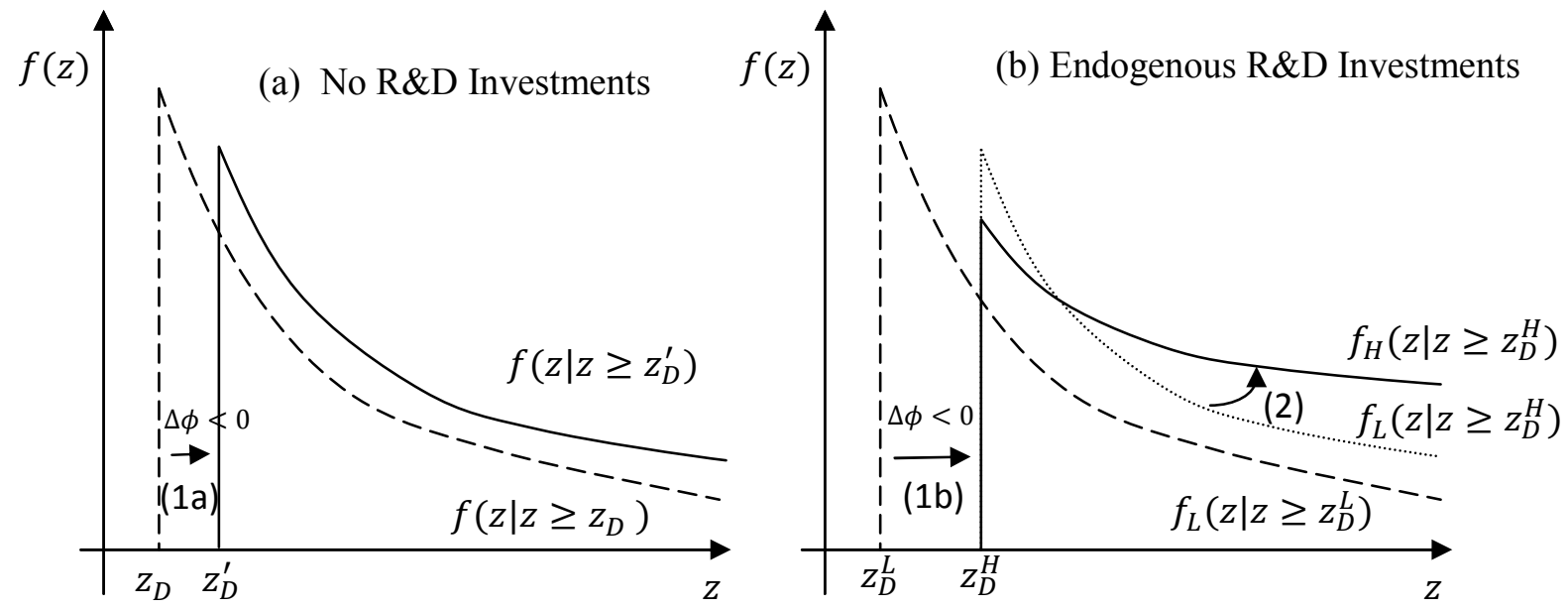

Figure 4: The impact of trade liberalization on the productivity distribution of all firms: (a) in a model without firm level $R \& D$ investments à la Melitz (2003); (b) in this model with firm level $R \& D$ investments.

Second, if all entrants invest in a high level of $R \& D$, the productivity distribution has a higher right tail compared to the case of no $R \& D$ investments (effect (2) in Figure 4). In equilibrium there are more highly productive firms. As a result, the domesticand export average productivity are larger compared to a model without $R \& D$ investments, $\tilde{z}_{D}^{H}>\tilde{z}_{D}^{\prime}(8)$ and $\tilde{z}_{X}^{H}>\tilde{z}_{X}^{\prime}(9)$ respectively, because $B_{H}>B$. This would even be the case if an increase of all entrants' $R \& D$ investments would have no impact on the selection effect, $z_{D}^{H}=z_{D}^{\prime}$. In addition, the share of export firms is also larger: 
$p_{X}^{H}=\phi^{\theta_{H}}>p_{X}^{\prime}=\phi^{\theta}$, due to $\theta>\theta_{H}$ and $0 \leq \phi \leq\left(\frac{f_{d}}{f_{x}}\right)^{1 /(\sigma-1)} \leq 1 .{ }^{19}$ This means more weight is now on exports inducing efficiency losses. But the increased number of export firms, that are on average more productive than the average of all firms, more than offsets the efficiency losses: $\frac{1+\tau^{1-\sigma} \phi^{\theta} H^{-\sigma+1}}{1+\phi^{\theta} H}>\frac{1+\tau^{1-\sigma} \phi^{\theta-\sigma+1}}{1+\phi^{\theta}} .{ }^{20}$ Thus, all effects that can be attributed to the increased $R \& D$ investments influence the sector productivity positively. Hence, $\tilde{z}_{H}>\tilde{z}^{\prime}$.

This is consistent with empirical evidence by Lileeva (2008); Bernard et al. (2006); Trefler (2004); Pavcnik (2002): trade liberalization boosts the aggregate productivity by a reallocation of resources from low productive exiting firms to high productive exporting firms and by productivity growth within firms. One important cause for the second effect seems to be increased innovation investments of firms in response to trade liberalization (Bustos, 2011; Lileeva and Trefler, 2010). In addition, other empirical studies show that the level of trade openness affects systematically the firm distribution of sectors. In particular, more trade openness leads to more right-skewed sector distributions (Okubo and Tomiura, 2013; Sun and Zhang, 2012; Di Giovanni et al., 2011). Furthermore, Maggioni (2013); Ito and Lechevalier (2009); Syverson (2004) document, at odds with previous heterogeneous firms models, trade liberalization increases the productivity dispersion among firms within a sector. The model in this paper provides an explanation for these evidence: trade liberalization triggers $R \& D$ investments of firms. As a result, the shape of a sector's firm distribution changes fundamentally in the long run.

\section{Discussion and related literature}

The following section first discusses modeling issues of the proposed $R \& D$ choice mechanism. Second, it embeds the model within the literature on heterogeneous firms and trade.

First of all it is notable that all other aggregate variables can be easily derived, because they are all solely determined by the cut-off productivity $z_{D}^{i}(13)$ and the sector productivity $\tilde{z}_{i}(23)$. Hence, it would be possible to analyze in a next step the effects of trade liberalization on welfare. However, it is not the purpose of this paper to analyze trade-induced innovations as a further form of gain from trade. An overview of the welfare gains of trade when firm heterogeneity is taken into account can be found, for

\footnotetext{
${ }^{19}$ The conditional probability in the case of a Pareto distribution is $P\left(z \geq z_{X} \mid z \geq z_{D}\right)=\left(\frac{z_{D}}{z_{X}}\right)^{\theta}$. The probabilities in the text are derived by using (4) in this expression.

${ }^{20}$ The inequality can be written as $1+\phi^{\theta-\sigma+1} \tau^{1-\sigma}+\phi^{\theta_{H}}+\phi^{\theta_{H}+\theta-\sigma+1} \tau^{1-\sigma}<1+\phi^{\theta_{H}-\sigma+1} \tau^{1-\sigma}+$ $\phi^{\theta}+\phi^{\theta_{H}+\theta-\sigma+1} \tau^{1-\sigma} \rightarrow \phi^{\theta}\left(\phi^{-\sigma+1} \tau^{1-\sigma}-1\right)<\phi^{\theta_{H}}\left(\phi^{-\sigma+1} \tau^{1-\sigma}-1\right)$, because $\tau^{1-\sigma} \phi^{-\sigma+1} \geq 1$ and $\phi^{\theta}<\phi^{\theta_{H}}$.
} 
example, in Melitz and Trefler (2012). ${ }^{21}$ The main aim of the paper is rather to build an analytically tractable general equilibrium framework, that is in important aspects consistent with recent empirical findings and can be extended in a variety of ways. Since numerous models assume firms to be Pareto-distributed, the $R \& D$ concept can be easily implemented in a large number of models. ${ }^{22}$ This might be especially useful in models quantifying aggregate effects of trade liberalization in calibration exercises. Most of these studies based on heterogeneous firms models assume Pareto distributed firms and take the shape parameter as exogenously given. However, the results of such analyses can be spurious if the effects of trade liberalization on the shape of the distribution is unconsidered (see for example Di Giovanni et al. (2011) for an empirical validation of changes in the shape parameter as trade becomes liberalized). The framework presented here offers one mechanism how this shortcoming can be solved. In addition, changes in the optimal $R \& D$ investment decision of firms in response to trade liberalization requires innovation returns differing according to the $H R S D$ criterion. The mathematical proof can be found in the Appendix. ${ }^{23}$ If the expected outcome of a high level of $R \& D$ would only FOSD and not $H R S D$ the outcome of a low level of $R \& D$, the optimal choice would be independent of the degree of trade openness $\phi$.

An example may illustrate this in the case of Pareto distributed firms. Assume a firm can choose between two Pareto distributions differing in the minimum support parameter: $z_{0 H}$ and $z_{0 L}$, with $z_{0 H}>z_{0 L}$. Applying the above definition of $H R S D(6)$, it turns out that the better distribution does not $H R D S$ the worse distribution, because $\frac{f_{H}(z)}{\bar{F}_{H}(z)}=\frac{\theta}{z}$ and $\frac{f_{L}(z)}{\bar{F}_{L}(z)}=\frac{\theta}{z}$. Hence, the optimal $R \& D$ choice will either be $z_{0 L}$ or $z_{0 H}$ for any degree of trade openness, depending on the investment costs $F_{L}$ and $F_{H}$. This can be seen by investigating the $R \& D$ choice function of an entrant. It is

$$
V\left(z_{D}^{L}, \phi\right)=\max \left\{0 ; \frac{z_{0 H}^{\theta}}{F_{L} z_{0 L}}-F_{H}\right\}
$$

if the general equilibrium value is determined by a low level of $R \& D$. Or

$$
V\left(z_{D}^{H}, \phi\right)=\max \left\{\frac{z_{0 L}^{\theta}}{F_{H} z_{0 H}}-F_{L} ; 0\right\} .
$$

\footnotetext{
${ }^{21}$ There is an ongoing discussion about the welfare gains from trade of heterogeneous firms models compared to homogenous firms models (Melitz and Redding, 2014; Arkolakis et al., 2012, 2008). The inclusion of $R \& D$ investments, as proposed here, would cause the elasticity of welfare with respect to variable trade costs to be interpreted as a function of the degree of trade openness. Hence, a welfare analysis within the present framework could contribute to this discussion.

${ }^{22}$ Redding (2011) discusses why the Pareto distribution is widely used in the literature on heterogeneous firms.

${ }^{23}$ The proof is done for the general case. Hence, this result is not restricted to Pareto distributions.
} 
if the general equilibrium value is determined by a high level of $R \& D$. Each time the value is independent of $\phi$.

However, the $H R S D$ criterion (6) is fulfilled if the distributions of innovation returns differ with respect to the shape parameter: $\frac{f_{H}(z)}{\bar{F}_{H}(z)}=\frac{\theta_{H}}{z}$ and $\frac{f_{L}(z)}{\bar{F}_{L}(z)}=\frac{\theta_{L}}{z} \rightarrow \frac{f_{H}(z)}{\bar{F}_{H}(z)}<\frac{f_{L}(z)}{\bar{F}_{L}(z)}$, because $\theta_{L}>\theta_{H}$.

What is the intuition for these different outcomes? Trade liberalization increases the minimum productivity that is required for a firm to survive. In the case of $H R S D$, the ex-ante relative survival rate of a high level to a low level of $R \& D$ investment increases in the failure cut-off $z_{D}: \frac{\partial \frac{\bar{F}_{H}\left(z_{D}\right)}{F_{L}\left(z_{D}\right)}}{\partial z_{D}}>0$. Why? Because disproportionately more draws lead to a low productivity in the case of low $R \& D$ investments compared to high $R \& D$ investments. This asymmetric outcome matters more, the higher a firm's productivity has to be to survive. Hence, the relative profitability of high to low $R \& D$ investments increase with trade liberalization. In contrast, if the outcomes between two investment possibilities differ according to the FOSD criterion but not to the $H R S D$ criterion, the ex-ante relative survival rate remains unchanged in the failure cut-off $z_{D}: \frac{\partial \frac{\bar{F}_{H}\left(z_{D}\right)}{F_{L}\left(z_{D}\right)}}{\partial z_{D}}=0$. Hence, trade liberalization does not affect the relative profitability of two $R \& D$ investment alternatives.

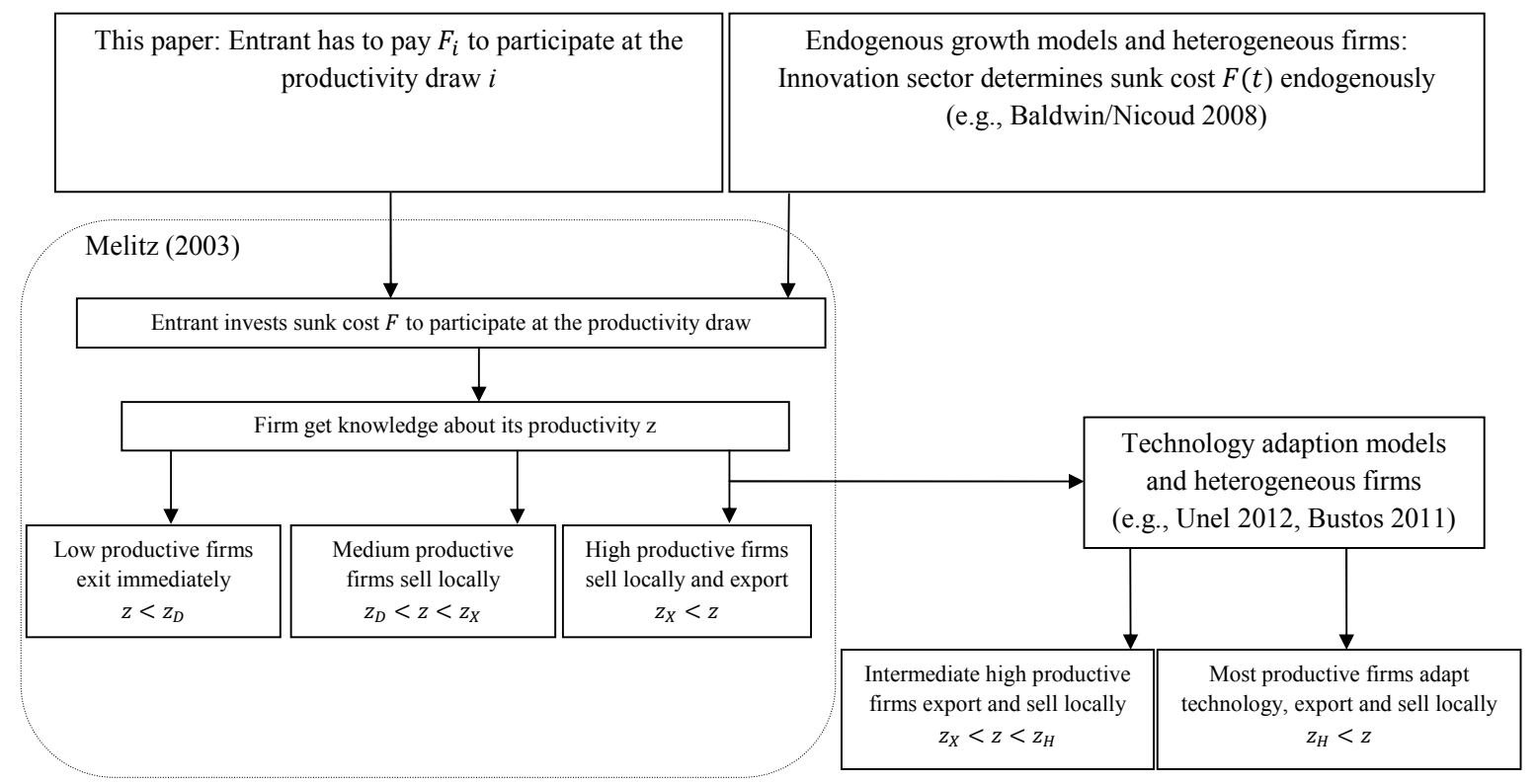

Figure 5: Placing the model in its proper research context.

The next paragraph describes how the framework of this paper complements other heterogeneous firms and trade models. Figure 5 shows it in a schematic way. Models of heterogeneous firms and endogenous growth (Unel, 2010; Gustafsson and Segerstrom, 2010; Baldwin and Nicoud, 2008) analyze how trade liberalization affects the general knowledge accumulation of an economy over time. In a technical way these models endogenize the sunk cost $F(t)$ that each entrant has to pay in Melitz (2003) in order 
to participate at the productivity draw. The cost depends on the units of knowledge created in an innovation sector up to a date $t$. The creation of knowledge over time depends on the degree of trade openness. Compared to the model at hand, such models do not consider endogenous $R \& D$ investments of firms in an "adapting industry". However, many researchers hypothesize that the evolution of general knowledge and innovations of adapting industries are jointly determined in the long run (Grossman and Helpman, 1994). Hence, a merge of both frameworks could help to understand better the role of globalization and its impact on aggregate productivity in a long term perspective. To build such a model seems possible, because both frameworks are based on Melitz (2003) with Pareto distributed firms.

Other models add a post-stage to the Melitz (2003) framework in which firms can adapt to a better technology after they got knowledge about their productivity (Unel, 2013; Bustos, 2011; Navas-Ruiz and Davide, 2007). If in these models a firm decides to adapt to another technology, it knows the benefits and costs. Hence, it can be seen as a rather short/medium run perspective in which some firms of an industry response to trade liberalization by miner changes of already existing production processes. Such changes have negligible uncertainty. An advantage compared to the model at hand is the heterogeneous responses of firms to trade liberalization in productivity enhancing measures. In contrast, the model at hand focuses on how trade liberalization affects investments in innovations in a long term perspective, in which firms discover entire new production processes. However, the assumption that entrants are identical previous to the productivity draw could be relaxed by several ways, e.g., by different sets of distributions from which entrants can draw their productivity. Probably the easiest way would be to assume different sunk costs among entrants for each type of $R \& D$ investment. ${ }^{24}$ Entrants with lower sunk costs would in such a setting find it profitable to invest at a lower degree of trade liberalization in a high level of $R \& D$. The general equilibrium value would then be determined by a mixed equilibrium. Nevertheless, the qualitative results of trade liberalization on the aggregate sector level would not be altered. In addition, a merge of the framework proposed here and technology adaption models would be feasible. The model of Unel (2013), which assumes Pareto-distributed firms, could serve as a point of reference. Such a combined framework would take into account the dual role of $R \& D$ claimed by many researchers. $R \& D$ investments generate new innovations and at the same time develops the ability of firms to better adapt to new technologies (Keller, 2004; Cohen and Levinthal, 1989).

\footnotetext{
${ }^{24}$ Such a setting would require hidden information about the sunk investment costs of entrants or capital that can only be invested in a specific type of entrant. Otherwise no investor would finance an entrant that needs a higher amount of sunk investment costs to gain the same expected return.
} 


\section{Conclusion}

This paper has introduced a new concept of firm innovations and trade liberalization in a heterogeneous firms general equilibrium model. For this purpose, it has extended the framework of Melitz (2003) by introducing endogenous investments in $R \& D$. $R \& D$ has been modeled as the discrete choice made by entrants to draw their productivity from different Pareto distributions (i.e., they differ with respect to the shape parameter). The research findings demonstrate that, in response to trade liberalization, firms now choose to invest more in $R \& D$ and draw from a better Pareto distribution compared to the distribution that was preferred prior to trade liberalization. This result is attributable to investment returns differing according to the hazard rate stochastic dominance criterion. If instead investment returns would differ only according to the first order stochastic dominance criterion, the optimal $R \& D$ decision of a firm would be independent of the degree of trade openness. Thus, trade liberalization influences the aggregate level through a reallocation of resources towards more productive firms and, novel to the literature, at the same time by a higher right tail of the firm productivity distribution. This is consistent with recent empirical work emphasizing both, the significance of reallocation of resources among firms and increased investments in innovations, to explain the effects of trade liberalization on sector productivity.

An advantage of this paper's model compared to other endogenous innovation trade models is its implementation in a well established framework. In a technical sense, it only makes one addition to the workhorse model of Melitz (2003) with Pareto distributed firms; yet with a remarkable effect. It enables most heterogeneous firms trade models to be extended in an analytically tractable way by introducing endogenous firm-level $R \& D$. In a closer context, this framework can be used as the basis to analyze how various aspects of industrial organization topics influence the long run $R \& D$ decisions of firms as trade becomes liberalized, for example concerning different demand structures or organization issues of production. Furthermore, it can be used in calibration studies analyzing the impact of trade liberalization to account for empirically relevant changes in the shape of a sector's firm distribution. In a larger context, it can be used to consider innovations on the firm level in endogenous growth models with heterogeneous firms à la Baldwin and Nicoud (2008). This could lead to a new theory on how trade liberalization, progress in basic research, and subsequent applied research of firms interact with each other. 


\section{Appendix}

\section{$N$-different $R \& D$ choices}

The assumption that an entrant can only choose between two different productivity distributions will now be extended to a large number of distributions. Assume there are $\mathrm{N}$, with $N \in \mathbb{N}$, different distributions from which entrants can draw their productivity. Each of them has another shape parameter $\theta_{i}=\theta_{1} ; \theta_{2} ; \ldots ; \theta_{N}$, with $\theta_{1}>\theta_{2}>\ldots>\theta_{N}$. Hence, the distribution with $\theta_{1}$ is stochastically dominated by all other distributions, and the distribution $\theta_{N}$ stochastically dominates all other distributions. Moreover, an entrant that draws from a better distribution has to invest more in $R \& D$ than if it were to draw from a worse distribution: $F_{1}<F_{2}<\ldots<F_{N}$. An entrant draws from the distribution that maximizes its expected profits:

$$
V\left(z_{D}, \phi\right)=\max \left\{V_{i}\left(z_{D}, \phi\right)\right\}, \text { where } i \in\{1,2, . ., N\} \text {. }
$$

From (18) and (20) it follows that

$$
\frac{\partial V_{i}\left(z_{D}^{j}\right)}{\partial \phi}=\left\{\begin{array}{l}
\ldots>0 \text { if } i>j \\
\ldots<0 \text { if } i<j, \\
\ldots=0 \text { if } i=j
\end{array}\right.
$$

with $j \in\{1,2 \ldots, N\}$ and $j \neq i$. Trade liberalization causes a decrease (increase) in the incentive to draw from a distribution that is stochastically dominated by (stochastically dominates) the currently preferred one. At the same time, trade liberalization changes the currently preferred distribution. Hence, further trade liberalization also changes whether it becomes more attractive or less attractive to draw form a distribution. In addition, from $F_{1}<\ldots<F_{N}$ it follows that

$$
\begin{aligned}
& \frac{\partial V_{i}\left(z_{D}^{j}\right)}{\partial F_{i}}<0, \\
& \frac{\partial V_{i}\left(z_{D}^{j}\right)}{\partial F_{j}}>0 .
\end{aligned}
$$

Hence, an entrant is indifferent between a maximum of two $R \& D$ choices at a particular level of trade openness $\phi^{*}$. Due to free entry, the expected profit for the optimal $R \& D$ choice is zero at the particular trade openness level $\phi^{*}$. At this particular level of trade openness, all other possible $R \& D$ choices lead to a negative expected profit. Due to (25), a further decline in trade costs to $\phi^{*}+\epsilon$, with $\epsilon>0$, could raise the expected profit of another than at $\phi^{*}$ optimal $R \& D$ choice above zero. In this case, entrants find it optimal to draw at $\phi^{*}+\epsilon$ from another distribution than at $\phi^{*}$. In addition, 
if investment costs in $R \& D$ rise proportionally more than the expected $R \& D$ gain, $\frac{\partial^{2} F}{\partial^{2} \theta}>\frac{\partial^{2} V}{\partial^{2} \theta}$, and at autarky an entrant prefers to draw from the worst distribution, $V_{1}\left(z_{D}, \phi=0\right)-F_{1}>\ldots>V_{N}\left(z_{D}, \phi=0\right)-F_{N}$, and at free trade, prefers to draw from the best distribution $V_{1}\left(z_{D}, \phi=1\right)-F_{1}<\ldots<V_{N}\left(z_{D}, \phi=1\right)-F_{N}$, then trade liberalization will constantly change the distribution towards being one from which entrants prefer to draw.

\section{Parameter conditions ensuring the existence of $\phi^{*}$}

Entrants find it under autarky optimal to invest in a low level of $R \& D$ if $V_{L}\left(z_{D}, \phi=\right.$ $0) \geq 0$ and $V_{H}\left(z_{D}, \phi=0\right)<0$ are fulfilled. Due to free entry $V_{L}\left(z_{D}, \phi=0\right)=0 \rightarrow$ $\left(B_{L}-1\right) f_{d}-F_{L} z_{D}^{\theta_{L}}=0$. Solve it after $z_{D}$ and use it in $V_{H}\left(z_{D}, \phi=0\right)$ leads to

$$
\left(B_{H}-1\right) f_{d}\left(\frac{F_{L}}{\left(B_{L}-1\right) f_{d}}\right)^{\frac{\theta_{H}}{\theta_{L}}}-F_{H}<0
$$

If this inequality is fulfilled entrants find it under autarky optimal to invest in a low level of $R \& D$. Furthermore, entrants find it optimal to invest in a high level of $R \& D$ at a certain degree of trade openness $\phi<\phi^{\max }$, with $\phi^{\max }=\left(\frac{f_{d}}{f_{x}}\right)^{\frac{1}{\sigma-1}} \leq 1$ since $\tau^{\text {min }} \rightarrow 1$, if $V_{L}\left(z_{D}, \phi\right)<0$ and $V_{H}\left(z_{D}, \phi\right) \geq 0$. Due to free entry $V_{H}\left(z_{D}, \phi\right)=0 \rightarrow$ $\left(B_{H}-1\right)\left(f_{d}+f_{x} \phi^{\theta_{H}}\right) z_{D}^{-\theta_{H}}-F_{H}=0$. Solve it after $z_{D}$ and use it in $V_{L}\left(z_{D}, \phi\right)<0$ leads to

$$
\left(B_{L}-1\right)\left(f_{d}+f_{x} \phi^{\theta_{L}}\right)\left(\frac{F_{H}}{\left(B_{H}-1\right)\left(f_{d}+f_{x} \phi^{\theta_{H}}\right.}\right)^{\frac{\theta_{L}}{\theta_{H}}}-F_{L}<0 .
$$

If the parameter values fulfill this condition, entrants find it from a certain degree of trade openness on optimal to invest in a high level of $R \& D$. Merge (28) and (29) together leads to

$$
\left(f_{d}+f_{x} \phi^{\theta_{L}}\right)\left(\frac{F_{H}}{\left(B_{H}-1\right)\left(f_{d}+f_{x} \phi^{\theta_{H}}\right)}\right)^{\frac{\theta_{L}}{\theta_{H}}}<\frac{F_{L}}{B_{L}-1}<f_{d}\left(\frac{F_{H}}{\left(B_{H}-1\right) f_{d}}\right)^{\frac{\theta_{L}}{\theta_{H}}} .
$$

This expression ensures that $V_{H}\left(z_{D}^{L}, \phi\right)$ and $V_{L}\left(z_{D}^{H}, \phi\right)$ crosses one time between $\phi=0$ and $\phi^{\max }$.

\section{The cut-off value at $\phi^{*}$}

Due to free entry, $V_{H}\left(z_{D}^{H}, \phi\right)=0$ and $V_{L}\left(z_{D}^{L}, \phi\right)=0$ have to be fulfilled for any level of trade openness. Hence, this also holds at $\phi^{*}$. In addition, an entrant is at $\phi^{*}$ indifferent between drawing from $\theta_{H}$ or $\theta_{L}: V_{H}\left(z_{D}^{L}, \phi\right)=V_{L}\left(z_{D}^{H}, \phi\right)$. This leads to the following 
system of equations:

$$
\begin{aligned}
\left(B_{H}-1\right)\left(f_{d}+f_{x} \phi^{\theta_{H}}\right) z_{D}^{L^{-\theta_{H}}}-F_{H}-\left(B_{L}-1\right)\left(f_{d}+f_{x} \phi^{\theta_{L}}\right) z_{D}^{H^{-\theta_{L}}}+F_{L} & =0, \\
\left(B_{H}-1\right)\left(f_{d}+f_{x} \phi^{\theta_{H}}\right) z_{D}^{H^{-\theta_{H}}}-F_{H} & =0, \\
\left(B_{L}-1\right)\left(f_{d}+f_{x} \phi^{\theta_{L}}\right) z_{D}^{L-\theta_{L}}-F_{L} & =0 .
\end{aligned}
$$

A solution is $z_{D}^{H}=z_{D}^{L}$. Because $\frac{\partial V_{L}\left(z_{D}^{H}\right)}{\partial \phi}<0$ and $\frac{\partial V_{H}\left(z_{D}^{L}\right)}{\partial \phi}>0$, there is at most one solution. Therefore, the only solution to this system of equations is $z_{D}^{H}=z_{D}^{L}$. In addition, $z_{D}^{m i x}$ is a weighted combination of $z_{D}^{H}$ and $z_{D}^{L}$ (see equation (13) and (14)). Hence, at $\phi^{*}$ it follows that $z_{D}^{\text {mix }}=z_{D}^{H}=z_{D}^{L}$.

\section{Proof that in order to get endogenous $R \& D$ adjustments of firms to trade liberalization, $H R S D$ is required}

For the following relations of stochastic orders see for example Shaked and Shanthikumar (2007). HRSD implies FOSD but not the other way around. The productivity distribution $F_{H}(z) H R S D$ the productivity distribution $F_{L}(z), F_{H}(z) \geq_{h r} F_{L}(z)$, if

$$
\frac{f_{h}(z)}{1-F_{H}(z)} \leq \frac{f_{L}(z)}{1-F_{L}(z)}
$$

In addition, $H R S D$ implies

$$
\frac{\bar{F}_{H}\left(z_{D}^{\prime}\right)}{\bar{F}_{H}\left(z_{D}\right)} \geq \frac{\bar{F}_{L}\left(z_{D}^{\prime}\right)}{\bar{F}_{L}\left(z_{D}\right)}
$$

for all $z_{D}^{\prime}>z_{D}$, with $\bar{F}(\cdot) \equiv 1-F(\cdot)$. The productivity distribution $F_{H}(z) F O S D$ the productivity distribution $F_{L}(z), F_{H}(z) \geq_{s t} F_{L}(z)$, if

$$
F_{H}(z)<F_{L}(z)
$$

In addition, if $F_{H}(z) \geq_{s t} F_{L}(z)$ but not $F_{H}(z) \geq_{h r} F_{L}(z)$, then

$$
\frac{\bar{F}_{H}\left(z_{D}^{\prime}\right)}{\bar{F}_{H}\left(z_{D}\right)}=\frac{\bar{F}_{L}\left(z_{D}^{\prime}\right)}{\bar{F}_{L}\left(z_{D}\right)}
$$

for all $z_{D} \neq z_{D}^{\prime}$. Furthermore, $H R D S$ implies

$$
E_{H}\left[y(z) \mid z>z_{D}\right]>E_{L}\left[y(z) \mid z>z_{D}\right],
$$


for any increasing function $y(z)$. However, FOSD implies only

$$
E_{H}[y(z)]>E_{L}[y(z)]
$$

Now to the model. The total expected profits net of sunk costs can be written for a not closer specified distribution function $F_{i}(z)$ as

$\bar{F}_{i}\left(z_{D}\right)\left(f_{d}\left(\frac{\left(\int_{z_{D}}^{\infty} z^{\sigma-1} f_{i}(z) d z\right)^{1 /(\sigma-1)}}{\bar{F}_{i}\left(z_{D}\right) z_{D}}-1\right)+\frac{\bar{F}_{i}\left(z_{X}\right)}{\bar{F}_{i}\left(z_{D}\right)} f_{x}\left(\frac{\left(\int_{z_{X}}^{\infty} z^{\sigma-1} f_{i}(z) d z\right)^{1 /(\sigma-1)}}{\bar{F}_{i}\left(z_{X}\right) z_{X}}-1\right)\right)$

with $P_{i}\left(z \geq z_{D}\right)=\bar{F}_{i}\left(z_{D}\right)$ as the probability of a successful entry into the domestic market and $\frac{\bar{F}_{i}\left(z_{X}\right)}{\bar{F}_{i}\left(z_{D}\right)}$ as the export probability conditioned on a successful domestic market entry (see Melitz (2003) for a step by step derivation). This is equivalent to equation (10) if $F_{i}(z)$ follows a Pareto distribution. (37) can be rewritten as

$$
\bar{F}_{i}\left(z_{D}\right)\left(f_{d}\left(E_{i}\left[\left(\frac{z}{z_{D}}\right)^{\sigma-1} \mid z>z_{D}\right]-1\right)+\frac{\bar{F}_{i}\left(z_{X}\right)}{\bar{F}_{i}\left(z_{D}\right)} f_{x}\left(E_{i}\left[\left(\frac{z}{z_{X}}\right)^{\sigma-1} \mid z>z_{X}\right]-1\right)\right),
$$

where $E_{i}[\cdot]$ is each corresponding conditional expectation value. Now we divide this expression with $i=H$ through $i=L$ :

$$
\frac{\bar{F}_{H}\left(z_{D}\right)\left(f_{d}\left(E_{H}\left[\left(\frac{z}{z_{D}}\right)^{\sigma-1} \mid z>z_{D}\right]-1\right)+\frac{\bar{F}_{H}\left(z_{X}\right)}{\bar{F}_{H}\left(z_{D}\right)} f_{x}\left(E_{H}\left[\left(\frac{z}{z_{X}}\right)^{\sigma-1} \mid z>z_{X}\right]-1\right)\right)}{\bar{F}_{L}\left(z_{D}\right)\left(f_{d}\left(E_{L}\left[\left(\frac{z}{z_{D}}\right)^{\sigma-1} \mid z>z_{D}\right]-1\right)+\frac{\bar{F}_{L}\left(z_{X}\right)}{\bar{F}_{L}\left(z_{D}\right)} f_{x}\left(E_{L}\left[\left(\frac{z}{z_{X}}\right)^{\sigma-1} \mid z>z_{X}\right]-1\right)\right)} .
$$

Each particular cut-off value, $z_{D}$ and $z_{X}$, has another value if trade openness changes, say from $\phi$ to $\phi^{\prime}$. Hence, this expression is at $\phi^{\prime}$

$$
\frac{\bar{F}_{H}\left(z_{D}^{\prime}\right)\left(f_{d}\left(E_{H}\left[\left(\frac{z}{z_{D}^{\prime}}\right)^{\sigma-1} \mid z>z_{D}^{\prime}\right]-1\right)+\frac{\bar{F}_{H}\left(z_{X}^{\prime}\right)}{\bar{F}_{H}\left(z_{D}^{\prime}\right)} f_{x}\left(E_{H}\left[\left(\frac{z}{z_{X}^{\prime}}\right)^{\sigma-1} \mid z>z_{X}^{\prime}\right]-1\right)\right)}{\bar{F}_{L}\left(z_{D}^{\prime}\right)\left(f_{d}\left(E_{L}\left[\left(\frac{z}{z_{D}^{\prime}}\right)^{\sigma-1} \mid z>z_{D}^{\prime}\right]-1\right)+\frac{\bar{F}_{L}\left(z_{X}^{\prime}\right)}{\bar{F}_{L}\left(z_{D}^{\prime}\right)} f_{x}\left(E_{L}\left[\left(\frac{z}{z_{X}^{\prime}}\right)^{\sigma-1} \mid z>z_{X}^{\prime}\right]-1\right)\right)},
$$

with $z_{D}^{\prime} \neq z_{D}$ and $z_{X}^{\prime} \neq z_{X}$. Now by using the above stated property for FOSD (34) it is obvious that $(39)=(40)$ if the distribution function $F_{H}(z)$ only FOSD and not $H R D S$ the distribution function $F_{L}(z)$. Since in this case $E_{H}[\cdot]=E_{L}[\cdot]$ (see equation $(35)$ and $(36))$. In addition, the fixed costs $f_{d}$ and $f_{x}$ have to be the same for both 
kinds of $R \& D$. Hence, in the case of FOSD but not $H R S D$ the profitability of a high level of $R \& D$ investments relative to a low level of $R \& D$ investments remains constant for any degree of trade openness. However, in the case of $H R S D$ it follows that $(39) \neq(40)$. As a result, in order that a firm's optimal $R \& D$ choice depends on the degree of trade openness, the expected outcomes of different $R \& D$ investments have to differ according to the $H R S D$ criterion. 


\section{References}

Amiti, M., Konings, J., 2007. Trade Liberalization, Intermediate Inputs, and Productivity: Evidence from Indonesia. The American Economic Review 97 (5), 1611-1638.

Arkolakis, C., Costinot, A., Rodríguez-Clare, A., 2012. New Trade Models, Same Old Gains? American Economic Review 102 (1), 94-130.

Arkolakis, C., Demidova, S., Klenow, P. J., Rodríguez-Clare, A., 2008. Endogenous Variety and the Gains from Trade. American Economic Review 98 (2), 444-50.

Atkeson, A., Burstein, A., 2010. Innovation, Firm Dynamics, and International Trade. The Journal of Political Economy 118(3), 433-484.

Baldwin, R., Nicoud, F., 2008. Trade and Growth with Heterogenous Firms. Journal of International Economics 74 (1), 21-34.

Bernard, A., Eaton, J., Jensen, B., Kortum, S., 2003. Plants and Productivity in International Trade. The American Economic Review 93 (4), 1268-1290.

Bernard, A., Jensen, B., Redding, S., Schott, P., 2012. The Empirics of Firm Heterogeneity and International Trade. Annu. Rev. Econ. 4 (1), 283-313.

Bernard, A., Jensen, B., Schott, P., 2006. Trade Costs, Firms and Productivity. Journal of Monetary Economics 53 (5), 917-937.

Bernard, A., Redding, S., Schott, P., 2011. Multiproduct Firms and Trade Liberalization. The Quarterly Journal of Economics 126 (3), 1271-1318.

Bohnstedt, A., Schwarz, C., Suedekum, J., 2012. Globalization and Strategic Research Investments. Research Policy 41 (1), 13-23.

Burstein, A., Melitz, M., 2011. Trade Liberalization and Firm Dynamics. In: Advances in Economics and Econometrics: Theory and Applications, Econometric Society Monographs.

Bustos, P., 2011. Trade Liberalization, Exports, and Technology Upgrading: Evidence on the Impact of Mercosur on Argentinian Firms. American Economic Review 101 (1), 304-40.

Chaney, T., 2008. Distorted Gravity: The Intensive and Extensive Margins of International Trade. American Economic Review 98 (4), 1707-1721.

Coad, A., Rao, R., 2008. Innovation and Firm Growth in High-tech Sectors: A quantile Regression Approach. Research Policy 37 (4), 633-648. 
Cohen, W., 2010. Chapter 4 - Fifty Years of Empirical Studies of Innovative Activity and Performance. In: Bronwyn, H. H., Nathan, R. (Eds.), Handbook of the Economics of Innovation. Vol. Volume 1. North-Holland, pp. 129-213.

Cohen, W., Levinthal, D., 1989. Innovation and Learning: The Two Faces of R\&D. The Economic Journal 99 (397), 569-596.

Costantini, J., Melitz, M., 2007. The Dynamics of Firm-level Adjustment to Trade Liberalization. The Organization of Firms in a Global Economy, 107-141.

Dasgupta, P., Stiglitz, J., 1980. Industrial Structure and the Nature of Innovative Activity. Economic Journal 90 (358), 266-93.

Di Giovanni, J., Levchenko, A. A., Ranciere, R., 2011. Power Laws in Firm Size and Openness to Trade: Measurement and Implications. Journal of International Economics 85 (1), 42-52.

Eaton, J., Kortum, S., Kramarz, F., 2011. An Anatomy of International Trade: Evidence from French Firms. Econometrica 79 (5), 1453-1498.

Ebersberger, B., Marsili, O., Reichstein, T., Salter, A., 2008. Fortune Favours the Brave: The Distribution of Innovative Returns in Finland, the Netherlands and the UK. Structural Change and Economic Dynamics 19 (4), 357-362.

Ederington, J., McCalman, P., 2008. Endogenous Firm Heterogeneity and the Dynamics of Trade Liberalization. Journal of International Economics 74 (2), 422-440.

Fernandes, A., 2007. Trade Policy, Trade Volumes and Plant-level Productivity in Colombian Manufacturing Industries. Journal of International Economics 71 (1), $52-71$.

Greenaway, D., Kneller, R., 2007. Firm Heterogeneity, Exporting and Foreign Direct Investment. The Economic Journal 117 (3), 134-161.

Grossman, G., Helpman, E., 1991. Innovation \& Growth in the Global. MIT Press.

Grossman, G., Helpman, E., 1994. Endogenous Innovation in the Theory of Growth. Journal of Economic Perspectives 8 (1), 23-44.

Gustafsson, P., Segerstrom, P., 2010. Trade Liberalization and Productivity Growth. Review of International Economics 18 (2), 207-228.

Helpman, E., 2006. Trade, FDI, and the Organization of Firms. Journal of Economic Literature 44(3), 589-630. 
Helpman, E., Melitz, M., Yeaple, S., 2004. Export Versus FDI with Heterogenous Firms. American Economic Review 94 (1), 300-316.

Impullitti, G., Irarrazabal, A., Opromolla, L., 2013. A Theory of Entry Into and Exit from Export Markets. Journal of International Economics 90 (1), 75 - 90.

Ito, K., Lechevalier, S., 2009. The Evolution of the Productivity Dispersion of Firms: A Reevaluation of its Determinants in the Case of Japan. Review of World Economics 145 (3), 405-429.

Keller, W., 2004. International Technology Diffusion. Journal of Economic Literature $42(3), 752-782$.

Leitner, S. M., Stehrer, R., 2011. Shapes and Determinants of Returns to Innovation. Economics of Innovation and New Technology 20 (8), 777-795.

Lileeva, A., 2008. Trade Liberalization and Productivity Dynamics: Evidence from Canada. Canadian Journal of Economics 41 (2), 360-390.

Lileeva, A., Trefler, D., 2010. Improved Access to Foreign Markets Raises Plant-level Productivity - For Some Plants. The Quarterly Journal of Economics 125 (3), 10511099.

Long, N., Raff, H., Stähler, F., 2011. Innovation and Trade with Heterogeneous Firms. Journal of International Economics 84 (2), 149-159.

Maggioni, D., 2013. Productivity Dispersion and its Determinants: the Role of Import Penetration. Journal of Industry, Competition and Trade 13 (4), 537-561.

Marsili, O., 2005. Technology and the Size Distribution of Firms: Evidence from Dutch Manufacturing. Review of Industrial Organization 27 (4), 303-328.

Marsili, O., Salter, A., 2005. Inequality of Innovation: Skewed Distributions and the Returns to Innovation in Dutch Manufacturing. Economics of Innovation and New Technology 14 (1-2), 83-102.

Melitz, M., 2003. The Impact of Trade on Intra-Industry Reallocations and Aggregate Industry Productivity. Econometrica 71 (6), 1695-1725.

Melitz, M., Ottaviano, G., 2008. Market Size, Trade, and Productivity. Review of Economic Studies 75 (1), 295-316.

Melitz, M., Redding, S., 2012. Heterogeneous Firms and Trade. Preliminary Draft.

Melitz, M., Trefler, D., 2012. Gains from Trade when Firms Matter. Journal of Economic Perspectives 26 (2). 
Melitz, M. J., Redding, S. J., 2014. Missing Gains from Trade? National Bureau of Economic Research Working Paper Series No. 19810.

Navas-Ruiz, A., Davide, S., 2007. Technology Adoption and the Selection Effect of Trade. Working Paper.

Okubo, T., Tomiura, E., 2013. Skew Productivity Distributions and Agglomeration: Evidence from Plant-Level Data. Regional Studies, 1-15Doi: 10.1080/00343404.2012.753143.

Pavcnik, N., 2002. Trade Liberalization, Exit, and Productivity Improvements: Evidence from Chilean Plants. The Review of Economic Studies 69 (1), 245-276.

Pflüger, M., Suedekum, J., 2013. Subsidizing Firm Entry in Open Economies. Journal of Public Economics 97, 258-271, 323.

Potin, J., 2009. The Selection Effect of Two-way Trade in the Melitz Model: An Alternative Approach. Working Paper.

Redding, S., 2011. Theories of Heterogeneous Firms and Trade. In: Arrow, K., Bresnahan, T. (Eds.), Annual Review of Economics. Vol. 3 of Annual Review of Economics. pp. $77-105$.

Romer, P., 1990. Endogenous Technological Change. Journal of Political Economy $98(5), 71-102$.

Scherer, F. M., Harhoff, D., 2000. Technology policy for a world of skew-distributed outcomes. Research Policy 29 (4), 559-566.

Segerstrom, P., 2011. Trade and Economic Growth. Palgrave Handbook of International Trade, Palgave Macmillan, 594-621.

Shaked, M., Shanthikumar, J. G., 2007. Stochastic Orders. Springer.

Sun, C., Zhang, T., 2012. Export, Productivity Pattern, and Firm Size Distribution. Working Paper.

Sutton, J., 1996. Technology and Market Structure. European Economic Review 40 (35), 511-530.

Syverson, C., 2004. Product Substitutability and Productivity Dispersion. Review of Economics and Statistics, 534-550.

Syverson, C., 2011. What Determines Productivity? Journal of Economic Literature 49 (2), 326-65. 
Tobin, J., 1969. A General Equilibrium Approach to Monetary Theory. Journal of Money, Credit and Banking 1 (1), 15-29.

Trefler, D., 2004. The Long and Short of the Canada-U.S. Free Trade Agreement. The American Economic Review 94 (4), 870-895.

Unel, B., 2010. Technology Diffusion through Trade with Heterogeneous Firms. Review of International Economics 18 (3), 465-481.

Unel, B., 2013. The Interaction Between Technology Adoption and Trade when Firms are Heterogeneous. Review of International Economics 21 (4), 797-808.

Vannoorenberghe, G., 2009. Trade Liberalization, Heterogeneous Firms and Endogenous Investment. Working Paper.

Yeaple, S., 2005. A Simple Model of Firm Heterogeneity, International Trade, and Wages. Journal of International Economics 65 (1), 1-20. 